NATIONAL LABORATORY

MANAGED BY UT-BATTELLE

FOR THE DEPARTMENT OF ENERGY

\title{
Dynamic Model Validation with Governor Deadband on the Eastern Interconnection
}

\section{April 2014}

Prepared by

Gefei Kou

Stanton W. Hadley

Yilu Liu

Approved for public release;

distribution is unlimited.

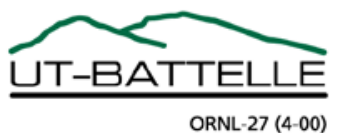




\section{DOCUMENT AVAILABILITY}

Reports produced after January 1, 1996, are generally available free via US Department of Energy (DOE) SciTech Connect.

Website http://www.osti.gov/scitech/

Reports produced before January 1, 1996, may be purchased by members of the public from the following source:

National Technical Information Service

5285 Port Royal Road

Springfield, VA 22161

Telephone 703-605-6000 (1-800-553-6847)

TDD 703-487-4639

Fax 703-605-6900

E-mail info@ntis.gov

Website http://www.ntis.gov/support/ordernowabout.htm

Reports are available to DOE employees, DOE contractors, Energy Technology Data Exchange representatives, and International Nuclear Information System representatives from the following source:

Office of Scientific and Technical Information

PO Box 62

Oak Ridge, TN 37831

Telephone 865-576-8401

Fax 865-576-5728

E-mail reports@osti.gov

Website http://www.osti.gov/contact.html

This report was prepared as an account of work sponsored by an agency of the United States Government. Neither the United States Government nor any agency thereof, nor any of their employees, makes any warranty, express or implied, or assumes any legal liability or responsibility for the accuracy, completeness, or usefulness of any information, apparatus, product, or process disclosed, or represents that its use would not infringe privately owned rights. Reference herein to any specific commercial product, process, or service by trade name, trademark, manufacturer, or otherwise, does not necessarily constitute or imply its endorsement, recommendation, or favoring by the United States Government or any agency thereof. The views and opinions of authors expressed herein do not necessarily state or reflect those of the United States Government or any agency thereof. 


\title{
DYNAMIC MODEL VALIDATION WITH GOVERNOR DEADBAND ON THE EASTERN INTERCONNECTION
}

\author{
Gefei Kou \\ Stanton W. Hadley \\ Yilu Liu
}

Date Published: April 2014

Prepared by

OAK RIDGE NATIONAL LABORATORY

Oak Ridge, Tennessee 37831-6283

managed by

UT-BATTELLE, LLC

for the

US DEPARTMENT OF ENERGY

under contract DE-AC05-00OR22725 



\section{Contents}

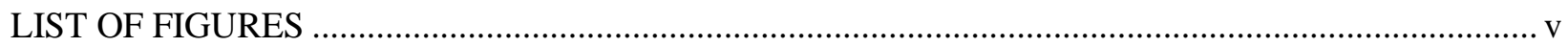

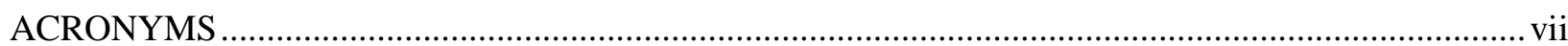

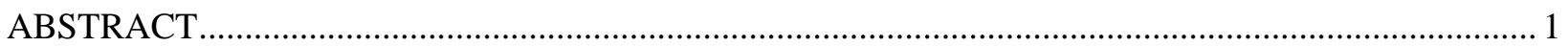

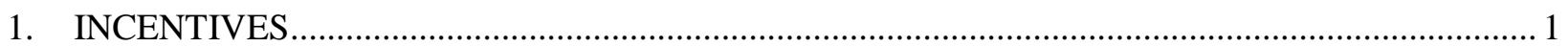

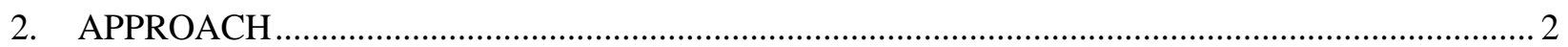

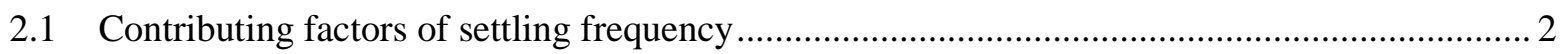

2.2 Turbine governor model conversion..................................................................... 4

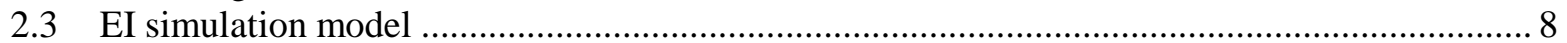

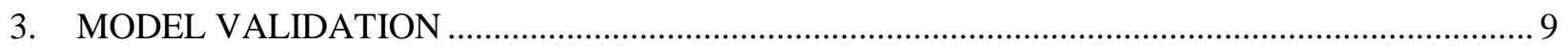

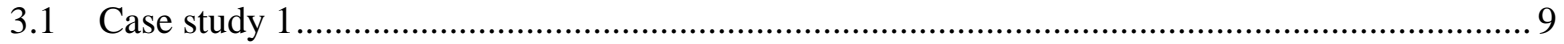

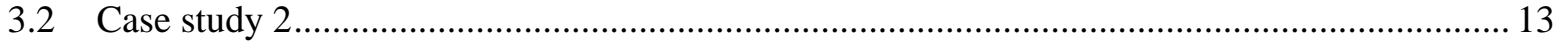

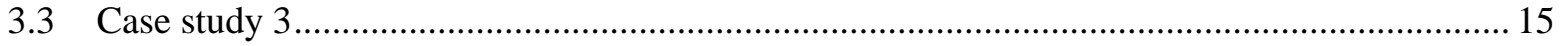

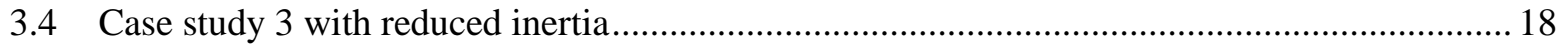

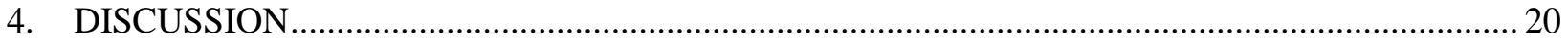

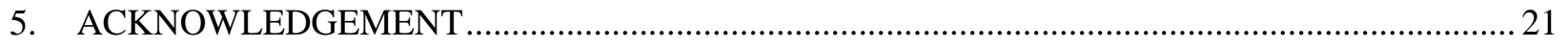

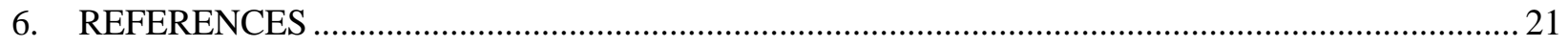





\section{LIST OF FIGURES}

Page

Fig. 1. Governor droop curve with 0.0006 per unit deadband. ............................................................2

Fig. 2. Mismatch between measurement and simulation in frequency response after generation trip. ........ 2

Fig. 3. Typical governor droop curve with 5\% speed regulation......................................................... 3

Fig. 4. Governor deadband with step-function implementation. ............................................................. 4

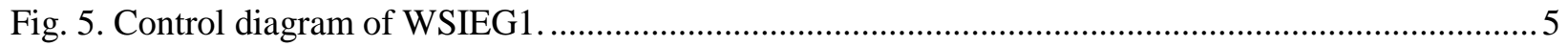

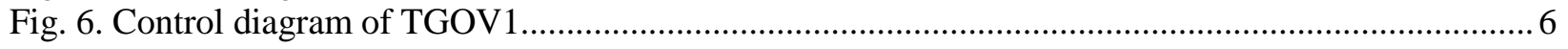

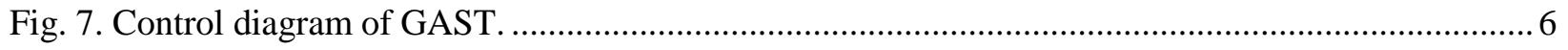

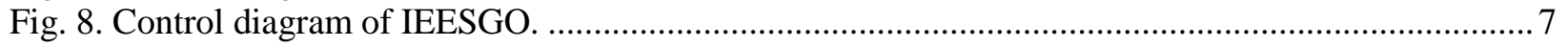

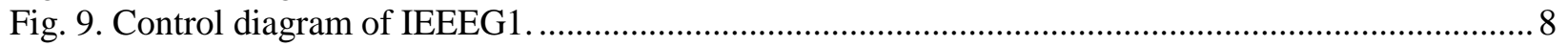

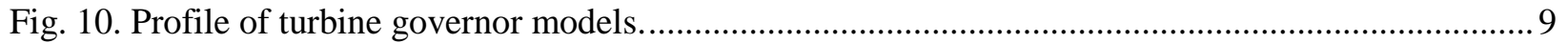

Fig. 11. Case study 1: measurement at Hampstead, North Carolina........................................................ 10

Fig. 12. Case study 1: measurement at Columbus, Ohio. ..................................................................... 10

Fig. 13. Case study 1: measurement at Boston, Massachusetts. …............................................................ 11

Fig. 14. Case study 1: measurement at Wakeeney, Kansas. .................................................................. 11

Fig. 15. Case study 1: measurement at Lakeland, Florida. ................................................................... 12

Fig. 16. Case study 1: measurement at Minneapolis, Minnesota.............................................................. 12

Fig. 17. Case study 1: measurement at Scott City, Missouri. .................................................................. 13

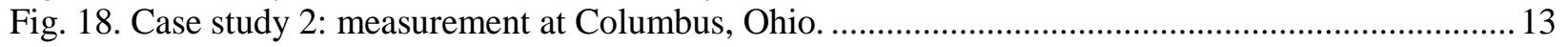

Fig. 19. Case study 2: measurement at Nashville, Tennessee................................................................. 14

Fig. 20. Case study 2: measurement at Minneapolis, Minnesota......................................................... 14

Fig. 21. Case study 2: measurement at Boston, Massachusetts. …..................................................... 15

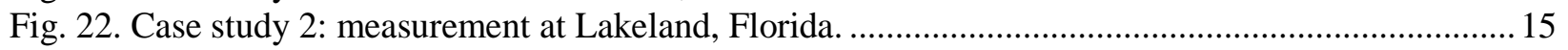

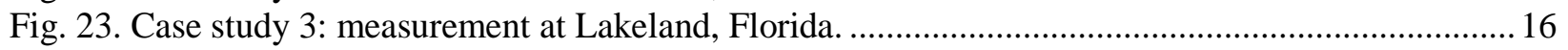

Fig. 24. Case study 3: measurement at Nashville, Tennessee............................................................ 16

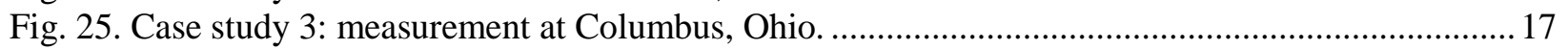

Fig. 26. Case study 3: measurement at Minneapolis, Minnesota........................................................... 17

Fig. 27. Case study 3: measurement at Boston, Massachusetts. ....................................................... 18

Fig. 28. Case study 3 with reduced inertia: measurement at Lakeland, Florida. ..................................... 18

Fig. 29. Case study 3 with reduced inertia: measurement at Nashville, Tennessee................................... 19

Fig. 30. Case study 3 with reduced inertia: measurement at Columbus, Ohio........................................ 19

Fig. 31. Case study 3 with reduced inertia: measurement at Minneapolis, Minnesota............................. 20

Fig. 32. Case study 3 with reduced inertia: measurement at Boston, Massachusetts. .............................. 20 



\section{ACRONYMS}

EI

FNET/GridEye

MVA

WECC
Eastern Interconnection

Frequency Monitoring Network

megavolt-ampere

Western Electricity Coordinating Council 



\begin{abstract}
This report documents the efforts to perform dynamic model validation on the Eastern Interconnection (EI) by modeling governor deadband. An on-peak EI dynamic model is modified to represent governor deadband characteristics. Simulation results are compared with synchrophasor measurements collected by the Frequency Monitoring Network (FNET/GridEye). The comparison shows that by modeling governor deadband the simulated frequency response can closely align with the actual system response.
\end{abstract}

\title{
1. INCENTIVES
}

Power system dynamic models are the fundamental tool to evaluate the stability of a perturbed electrical system. It is therefore crucial that models are validated against measurement recordings to reflect real system performance. In Federal Energy Regulatory Commission Order No. 693, the Commission directs "a requirement that the models be validated against actual system responses" and "that actual system events be simulated and if the model output is not within the accuracy required, the model shall be modified to achieve the necessary accuracy.” To address those directives, the North American Electric Reliability Corporation developed two standards: Data for Power System Modeling and Analysis (MOD032-1) and Steady-State and Dynamic System Model Validation (MOD-033-1). Those standards require that consistent modeling data be reported and updated on a periodic basis and that assembled models be validated against actual recordings. Meanwhile, it has been found that there is significant mismatch between event recordings and simulation results both in Eastern Interconnection (EI) and Western Interconnection (WECC) [1], [2]. The simulated frequency response is generally more optimistic than realistic. Therefore, there have been continuous efforts to minimize the mismatch by improving the model accuracy [3]-[5].

To reduce controller activities and turbine mechanical wear for normal power system frequency variations, a deadband is inserted to the governor droop characteristic so that the turbine will not react to the generator shaft speed excursion until it reaches a preset value (Fig.1). Modeling governor deadband comes into sight because of two major facts: first, a typical size of the governor deadband is $36 \mathrm{mHz}$ [6]. Multiplying this number by the average EI beta value, which is $2363 \mathrm{MW} / 0.1 \mathrm{~Hz}$ [6], the equivalent generation capacity to the typical deadband is $851 \mathrm{MW}$. This means that the loss of a small or even midsize generation unit will not immediately initiate the primary frequency control. Rather, the frequency will keep going down because of the power mismatch until the deviation exceeds the governor deadband. Then, the turbine system will start to compensate for the power loss and arrest the frequency excursion. Because of the delayed governor action, the system frequency is subject to a larger deviation.

The other fact is described in [6] and states that "pre-disturbance (average) frequency (Value A) is another statistically significant contributor to the variability of frequency response. The expected frequency response for events where Value A is greater than $60 \mathrm{~Hz}$ is $2188 \mathrm{MW} / 0.1 \mathrm{~Hz}$ versus 2513 MW/0.1 Hz for events where Value A is less than or equal to $60 \mathrm{~Hz}$.” This observation can be explained by governor deadband: as governor deadband is centered at the nominal frequency, when the predisturbance frequency is over $60 \mathrm{~Hz}$, the system frequency needs to drop more to touch the deadband. Consequently, the beta value would be smaller if the pre-disturbance frequency is greater than $60 \mathrm{~Hz}$. Therefore, in this study efforts are made to evaluate the impact of governor deadband in simulation. 


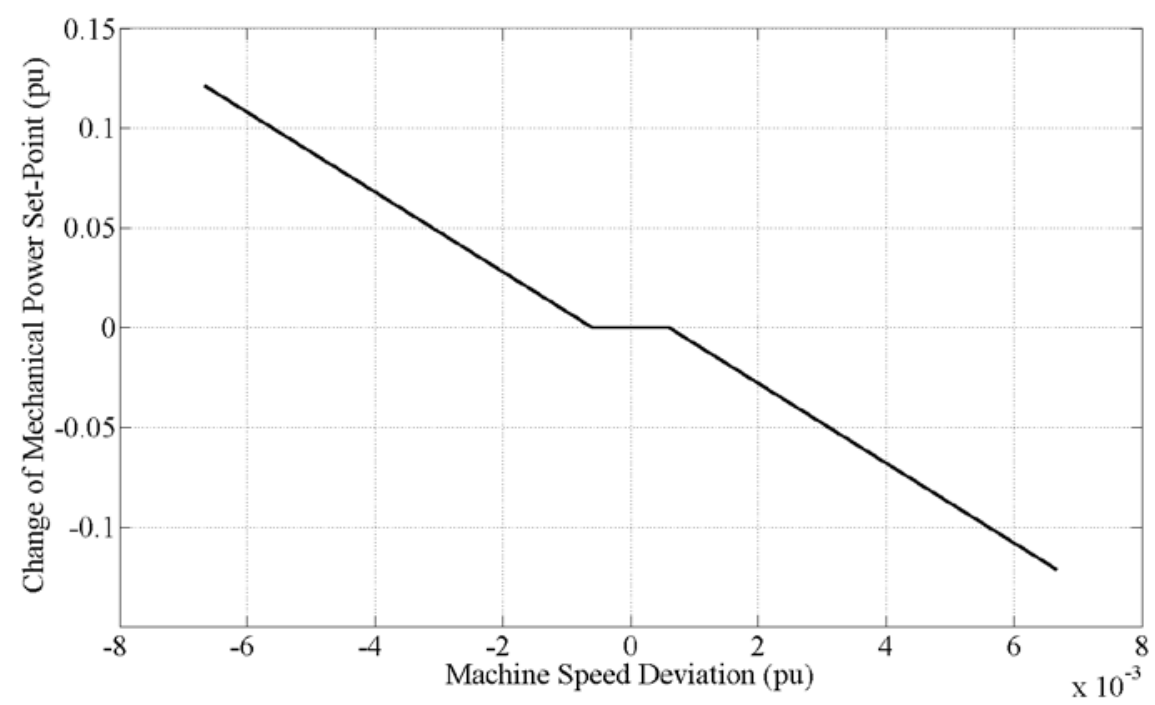

Fig. 1. Governor droop curve with 0.0006 per unit deadband.

\section{APPROACH}

\subsection{CONTRIBUTING FACTORS OF SETTLING FREQUENCY}

It has been observed that the EI simulated frequency response (the beta value) is larger than measurements. An example is shown in Fig. 2. Generally, the settling frequency can be attributed to the following factors.

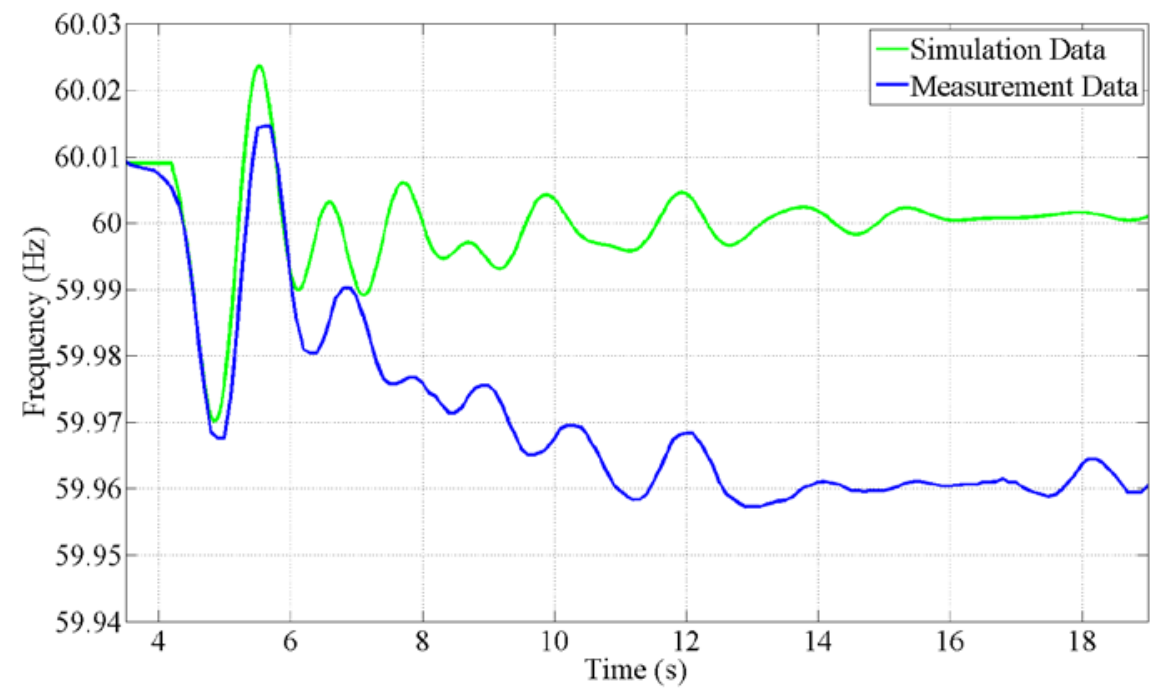

Fig. 2. Mismatch between measurement and simulation in frequency response after generation trip. 
As defined in [7], the fraction of capacity providing governing response, $K_{t}$, is a major factor of system frequency response. Nuclear and large fossil fuel plants are usually base loaded and do not contribute to frequency excursion. Some other generation units have their governor control loop bypassed so that their mechanical power set-point is fixed. As less generation resource is participating in the frequency response, the frequency deviation tends to be larger so that the participating units will generate more.

Load composite is also a contributing factor to frequency response. Electrical motors draw less power when the frequency is lower than the nominal and provide positive damping on frequency. The load composite ratio of the ZIP model can also make a difference. Generation loss often accompanies local voltage drop that reduces the power consumption of constant current and constant admittance load. Thus, the net generation loss is lower than the capacity of the tripped unit, as demand is reduced with lower voltage. However, this statement might not always hold true, considering that the excitation system would automatically regulate the bus voltage within a short period of time.

The power mismatch within the system will cause frequency to deviate from its nominal value. Until a new balance is met, frequency will continuously drift away. To prevent large frequency excursions, the primary frequency control is employed so that generators providing governor response would adjust their mechanical power set-point immediately to offset the power mismatch. An example of the droop curve is shown in Fig. 3. The slope of the curve is represented by the speed regulation $\boldsymbol{R}$, which is defined in Eq. (2.1). $\Delta P_{\text {mech }}$ and $\Delta \omega$ are per unit values and are based on machine megavolt-ampere (MVA) rating and nominal frequency, respectively. By adopting the per-unit value, the total power mismatch is equally divided to each machine based on its capacity. The speed regulation $R$ has a typical range of 3 to 5\% [8], and a smaller value of $R$ means a stronger governor response.

$$
\frac{1}{R}=-\frac{\Delta P_{m e c h}}{\Delta \omega}
$$

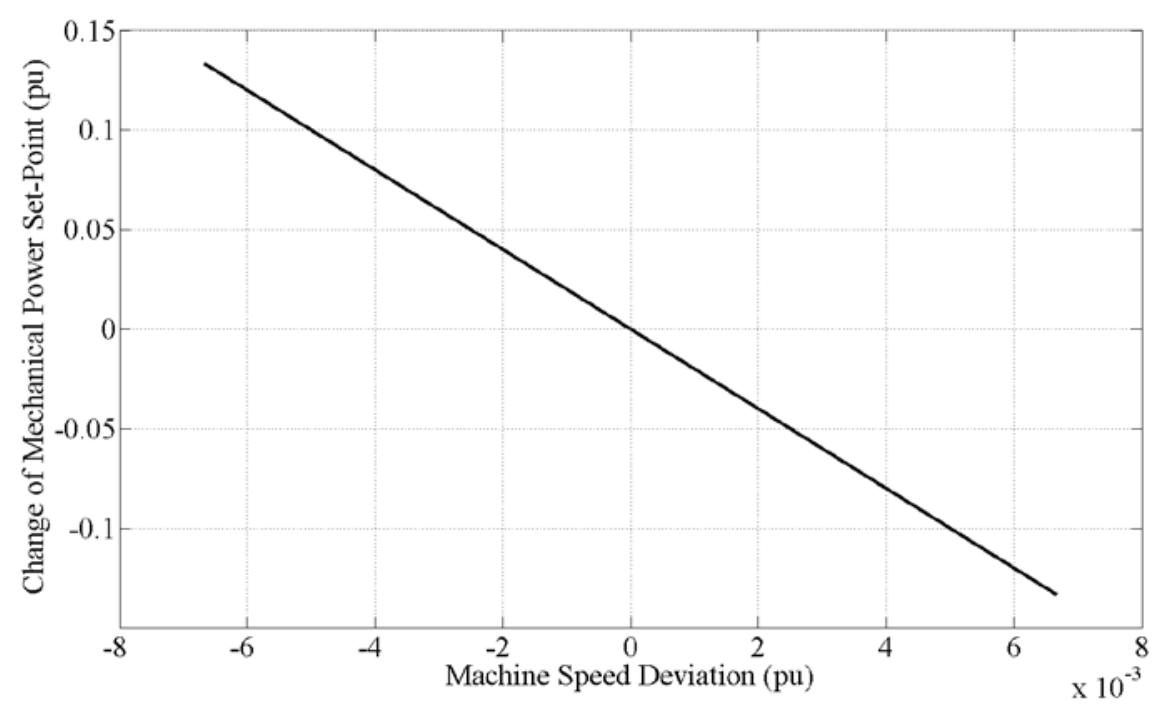

Fig. 3. Typical governor droop curve with $5 \%$ speed regulation.

The load controller is another contributing factor of frequency response [2]. A turbine governor with load controller would gradually reset its mechanical power to the pre-disturbance set-point depending on the proportional-Integral integral controller parameters. As a consequence, the frequency deviation would be enlarged because of the power withdrawal. 
From the viewpoint of dynamic simulation, the machine damping coefficient $\boldsymbol{D}$ has a significant impact on settling frequency. As shown in the swing Eq. (2.2), the machine damping coefficient $D$ represents the combined effects of machine electrical damping, turbine damping, and load damping. However, cautions have to be exercised on the use of $D$. For the constant-voltage-behind-transient-reactance machine model (GENCLS), as amortisseur circuits are not modeled, $D$ partly approximates the damper winding effect during the first swing [12]. However, this practice fails to recognize the fact that the damping torque is frequency dependent rather than being proportional to frequency deviation [9]. In addition, the electrical damping effect would die out once the machine speed stabilizes, while in simulation the damping torque still exists as long as there is static frequency deviation. The consequence is that the electrical damping component of $D$ would offset generation loss or load shedding and cause better damped simulation results. As for detailed round-rotor and salient-pole machine models, amortisseur circuits are represented. No electrical damping needs to be equivalent by $D$. Load damping has to be modeled with care, while the turbine governor system is modeled separately.

$$
P_{m}-P_{e}=\frac{2 H}{w_{R}} \dot{\Delta \omega}+D \Delta \omega
$$

Governor deadband could be another major factor for settling frequency as illustrated by this study. It is reported in [6] that governor deadband is widely implemented in the EI, with the smallest generating units having the lowest governor deadband, followed by the mid-size and then the largest units. Because of the deadband, frequency deviation has to exceed a certain value to trigger the governor to act. Thus, by modeling the deadband, the static frequency deviation would be larger compared with the no-deadband case. There are two types of implementation of deadband: no-step-function implementation (Fig.1) and step-function implementation (Fig. 4). In this study, the no-step-function implementation is investigated.

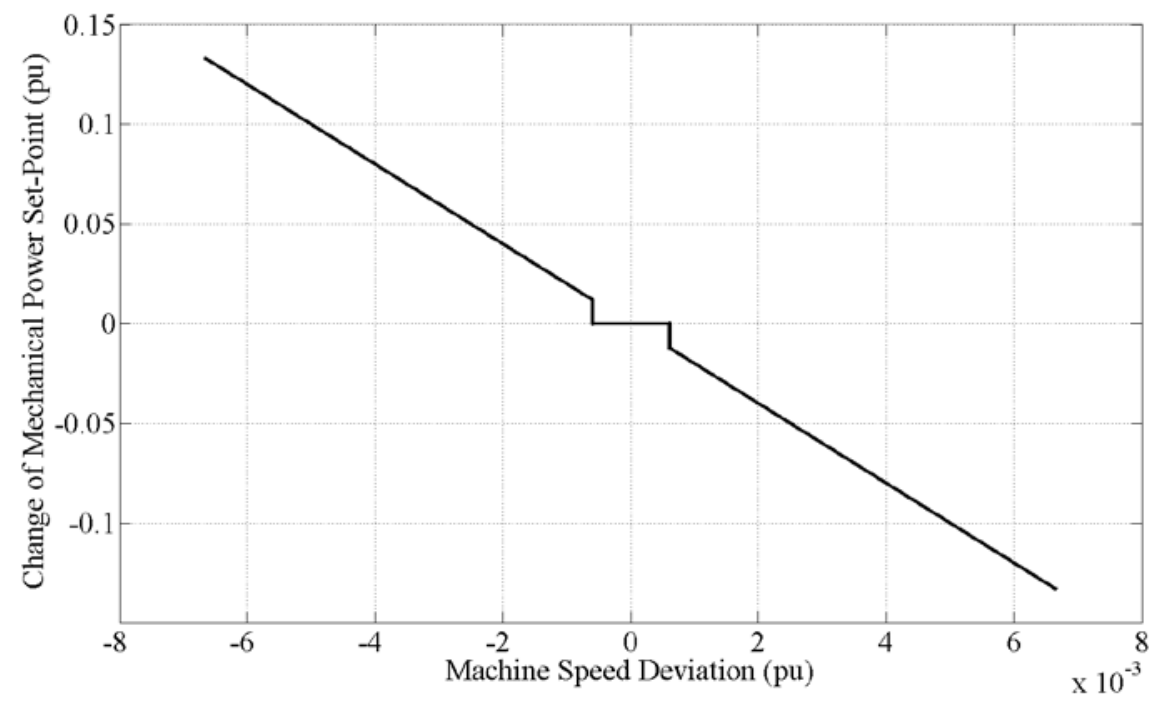

Fig. 4. Governor deadband with step-function implementation.

\subsection{TURBINE GOVERNOR MODEL CONVERSION}

Typical turbine governor models do not represent governor deadband. To represent governor deadband, existing governor models with dominant percentage are equivalently converted to a WSIEG1 model [10], which is the WECC modified IEEE type 1 speed-governing model. The following four types of turbine 
governor models, TGOV1, GAST, IEESGO, and IEEEG1, are converted to WSIEG1. The parameter conversion equations are listed subsequently. The WSIEG1 parameters are listed on the left-hand side of the equations. The parameters of the converted models are listed on the right side.

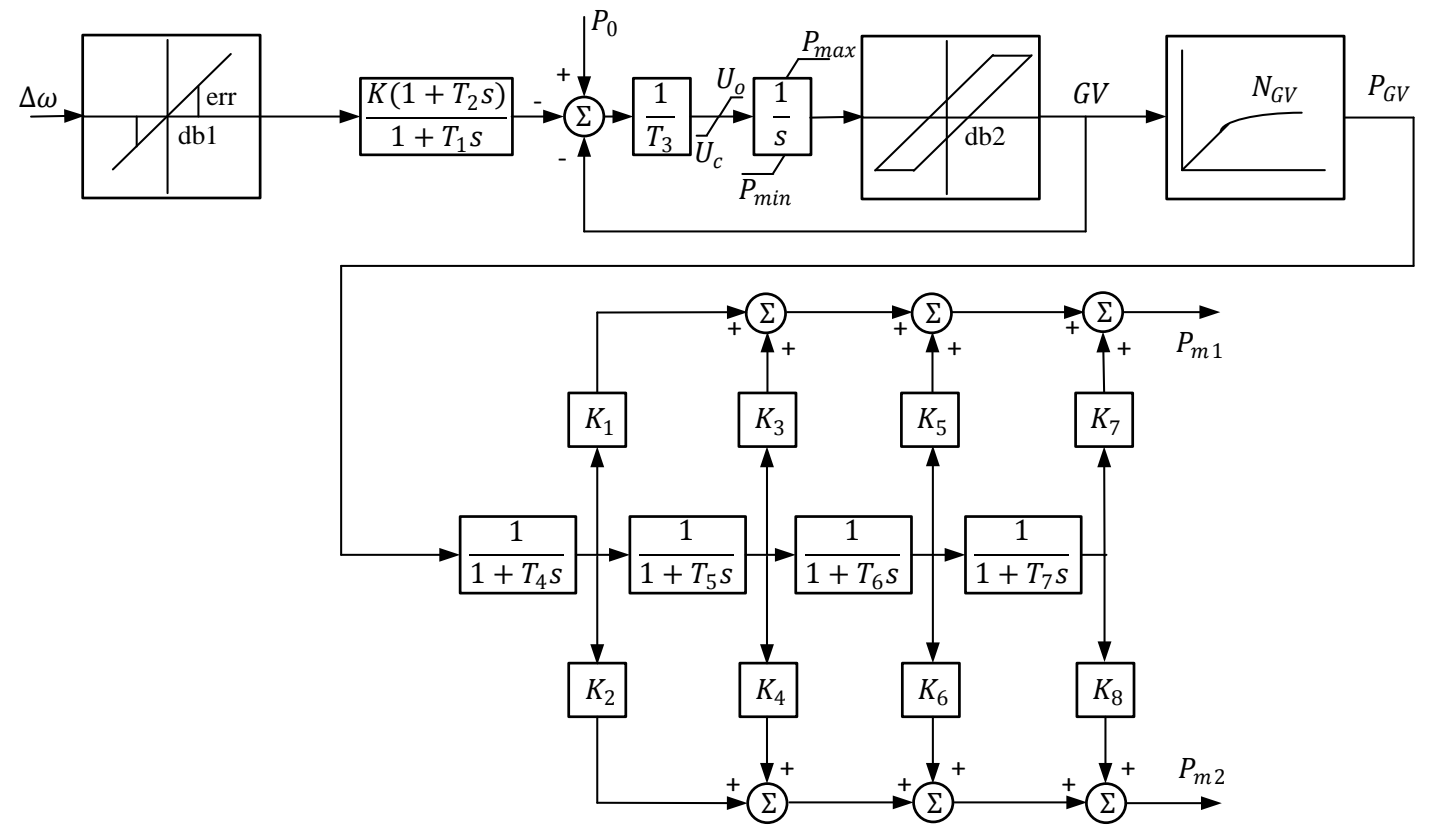

Fig. 5. Control diagram of WSIEG1.

To convert TGOV1 (Fig. 6) to WSIEG1:

$$
\begin{aligned}
& K=1 / R . \\
& T_{3}=T_{1} . \\
& K_{1}=T_{2} / T_{3} . \\
& K_{3}=1-T_{2} / T_{3} . \\
& T_{5}=T_{3} .
\end{aligned}
$$




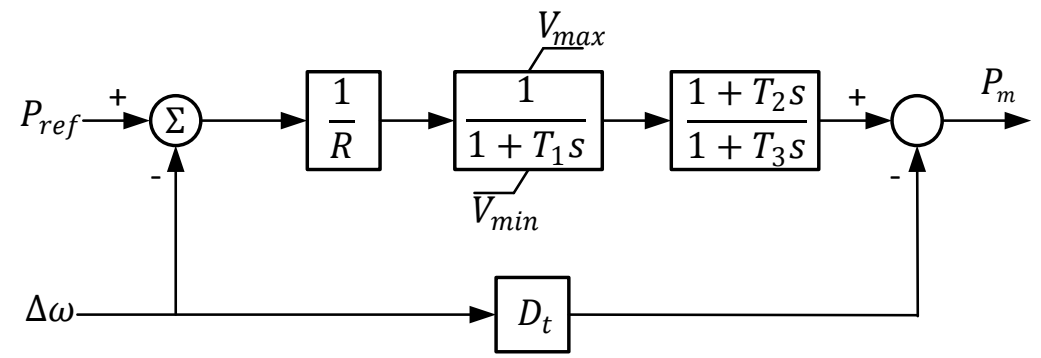

Fig. 6. Control diagram of TGOV1.

To convert GAST (Fig. 7) to WSIEG1, the load limit loop is not represented:

$$
\begin{gathered}
K=1 / R . \\
T_{3}=T_{1} . \\
T_{4}=T_{2} . \\
K_{1}=1 .
\end{gathered}
$$

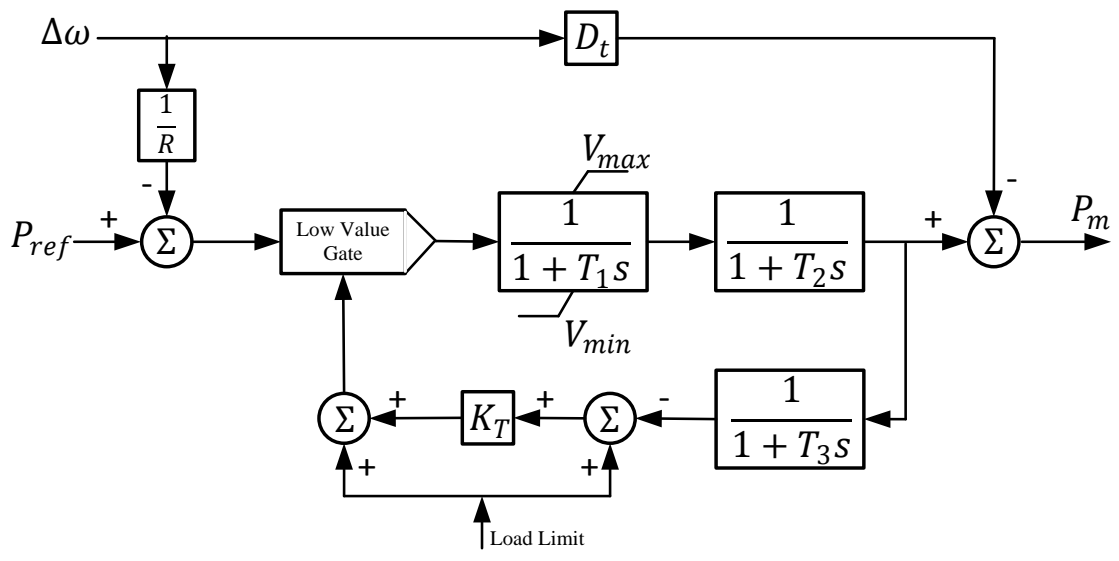

Fig. 7. Control diagram of GAST.

To convert IEESGO (Fig. 8) to WSIEG1:

$$
\begin{aligned}
& K=K_{1} . \\
& T_{1}=T_{1} . \\
& T_{2}=T_{2} .
\end{aligned}
$$




$$
\begin{aligned}
& T_{3}=T_{3} . \\
& T_{4}=T_{4} . \\
& K_{1}=1-K_{2} . \\
& K_{3}=K_{2}\left(1-K_{3}\right) . \\
& K_{5}=K_{2} K_{3} . \\
& T_{5}=T_{5} . \\
& T_{6}=T_{6} .
\end{aligned}
$$

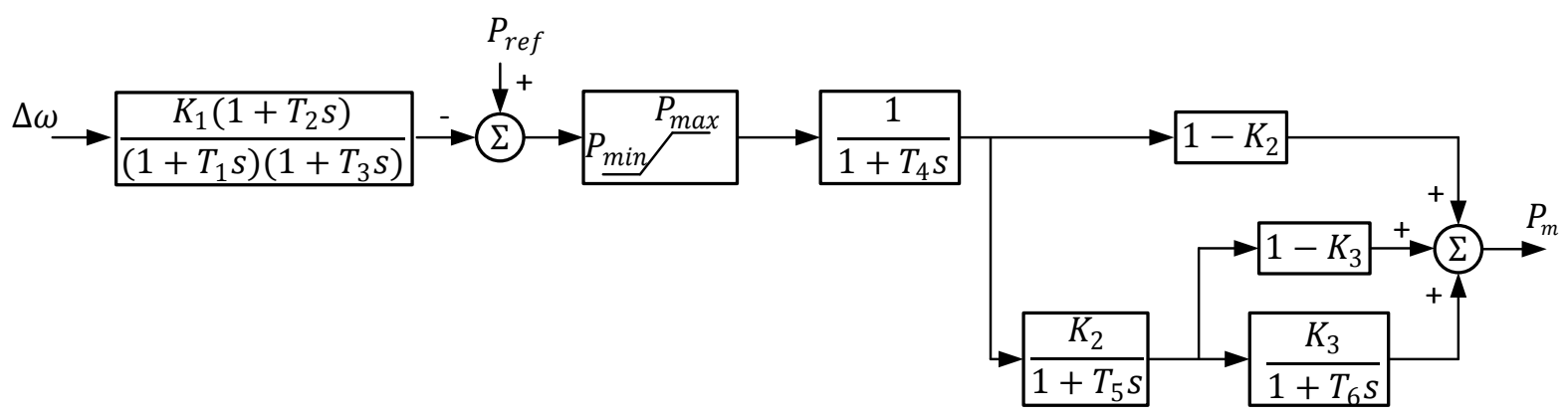

Fig. 8. Control diagram of IEESGO.

IEEEG1 (Fig. 9) is compatible with WSIEG1, so no parameter conversion is necessary. 


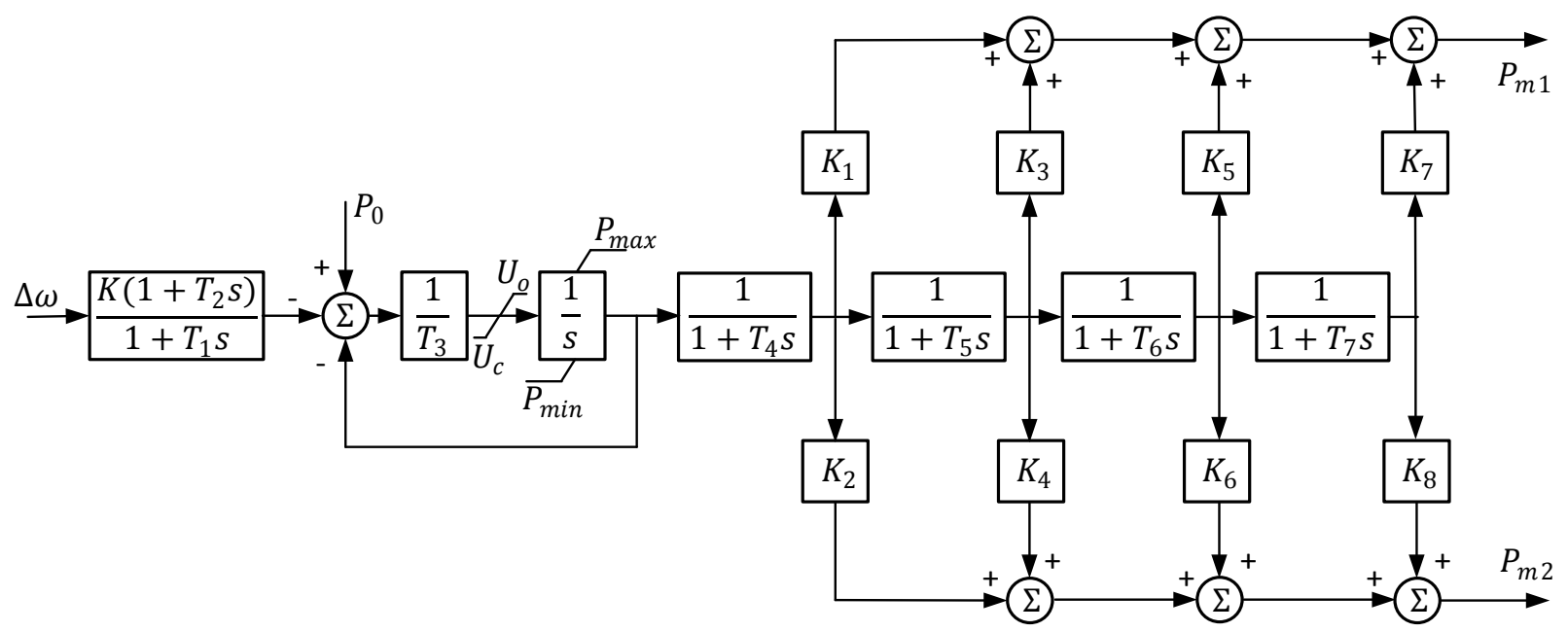

Fig. 9. Control diagram of IEEEG1.

\subsection{EI SIMULATION MODEL}

The EI simulation model has a capacity of $591 \mathrm{GW}$ with 16,000+ buses. The capacity of the installed excitation model amounts to $309 \mathrm{GW}$, and the capacity of the installed governor model equals $268 \mathrm{GW}$. As discussed in Sect. 2.2, the most dominant four types of governor are converted to WSIEG1, which has a total capacity of $247 \mathrm{GW}$. The rest of governor models are abandoned. Throughout the simulation, switched shunt is fixed. In addition, to eliminate the wrong representation of frequency damping caused by the damping coefficient of GENCLS, all GENCLS are replaced with GENROU assuming typical parameters [8]. The profile of the turbine governor model of the original system is shown in Fig. 10. 


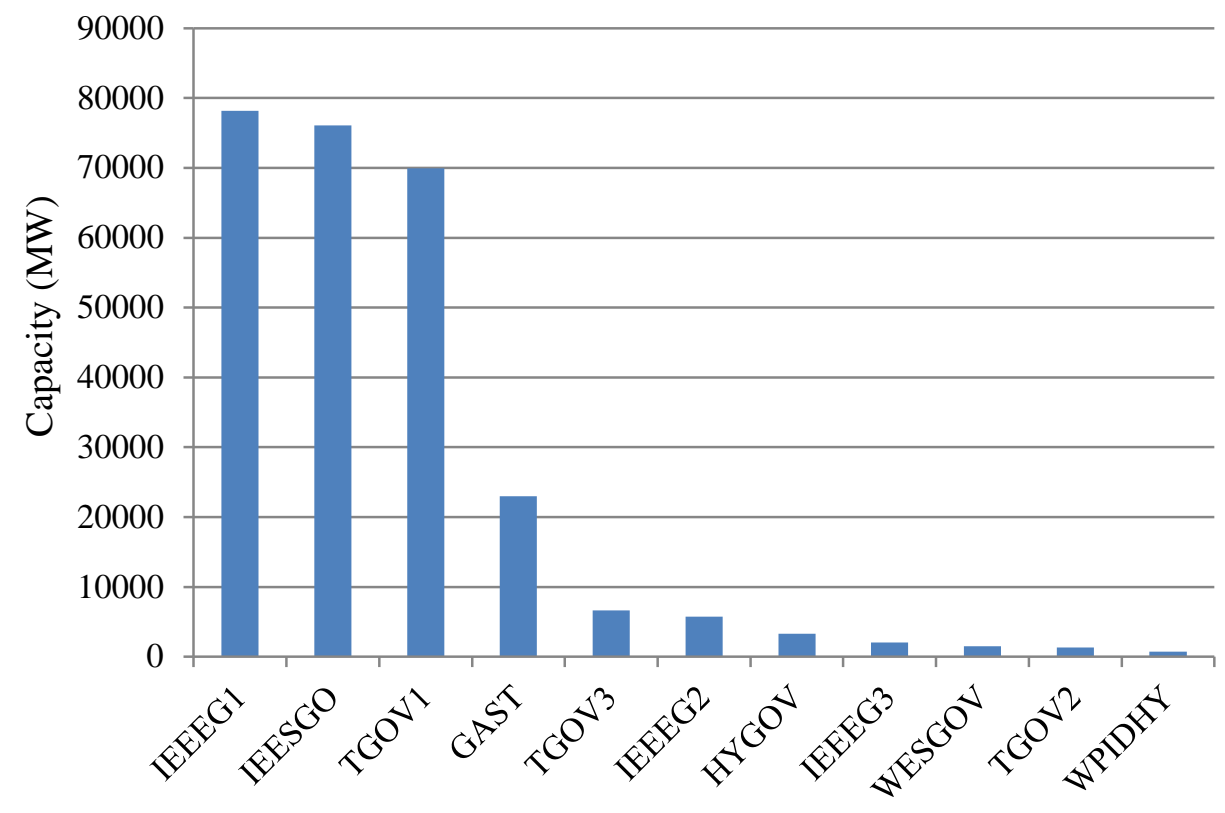

Fig. 10. Profile of turbine governor models.

\section{MODEL VALIDATION}

To perform model validation, actual generation trip recordings are compared with simulation results. The recorded synchrophasor data are collected by the FNET/GridEye system [11]. In the simulation model, governor deadband is adjusted uniformly so that the settling frequency matches up with the measurement. As the initial value is fixed at the nominal, the simulated frequency is adjusted vertically to align with the recorded pre-disturbance frequency. The time axis is adjusted in the manner that the ring-down traces are aligned at the most nearby observation point to the disturbance. For each event, several widely located observation points are chosen. The simulated frequency is selected on the bus that is geographically close to the measurement point.

\subsection{CASE STUDY 1}

Time: 02/21/2013 14:57:00 UTC

Actual event: 1100 MW generation trip at McGuire Unit 1 in North Carolina

Tripped capacity in simulation: $1100 \mathrm{MW}$

Governor deadband: $39 \mathrm{mHz}$ 


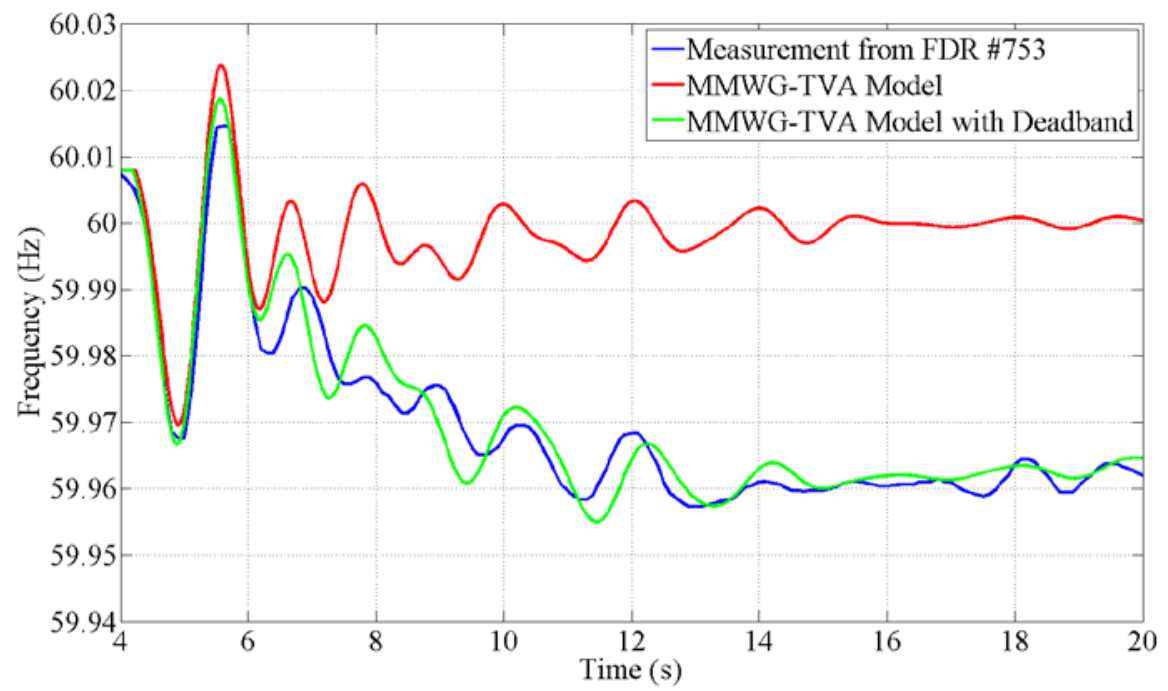

Fig. 11. Case study 1: measurement at Hampstead, North Carolina.

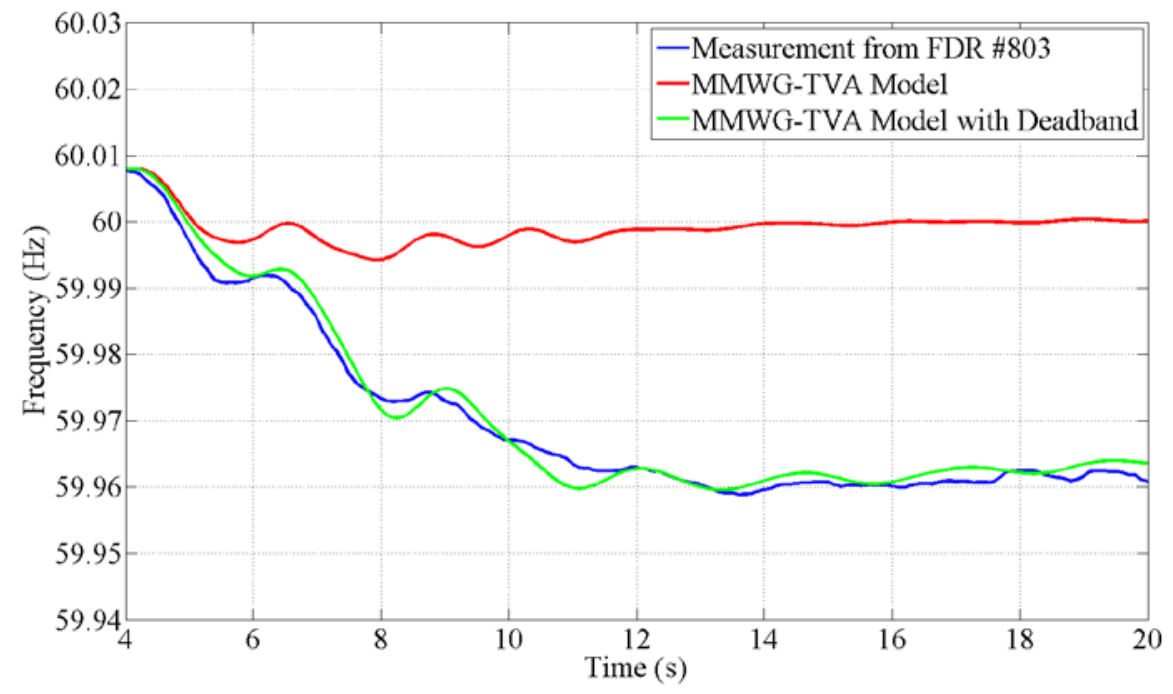

Fig. 12. Case study 1: measurement at Columbus, Ohio. 


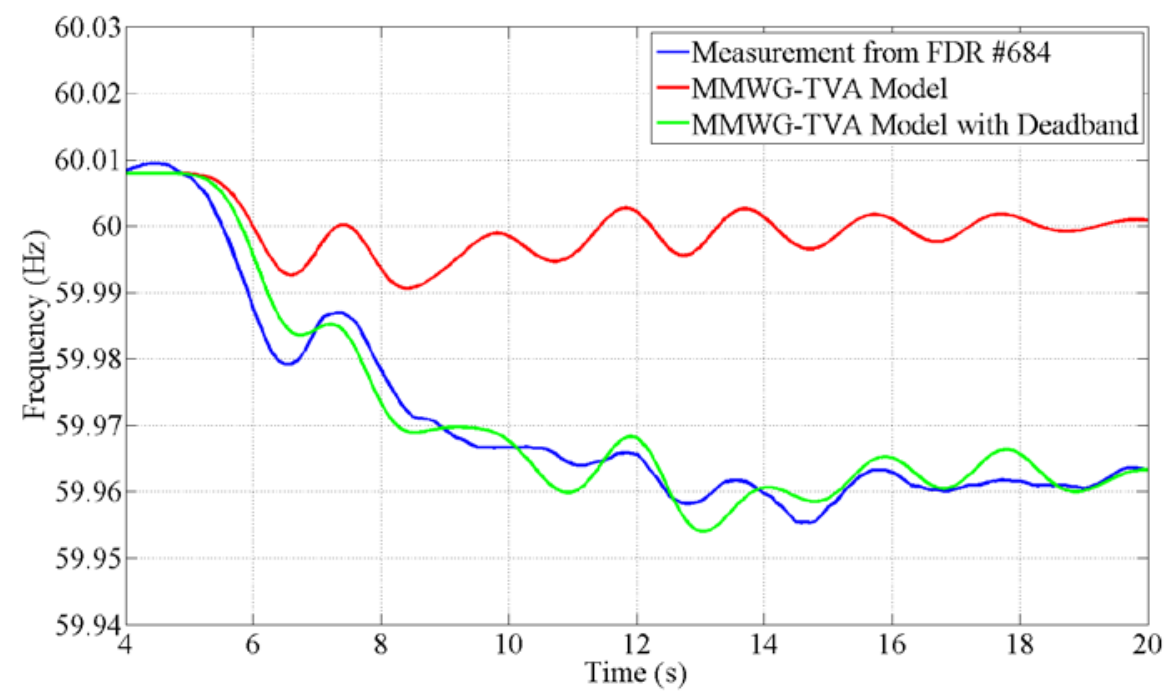

Fig. 13. Case study 1: measurement at Boston, Massachusetts.

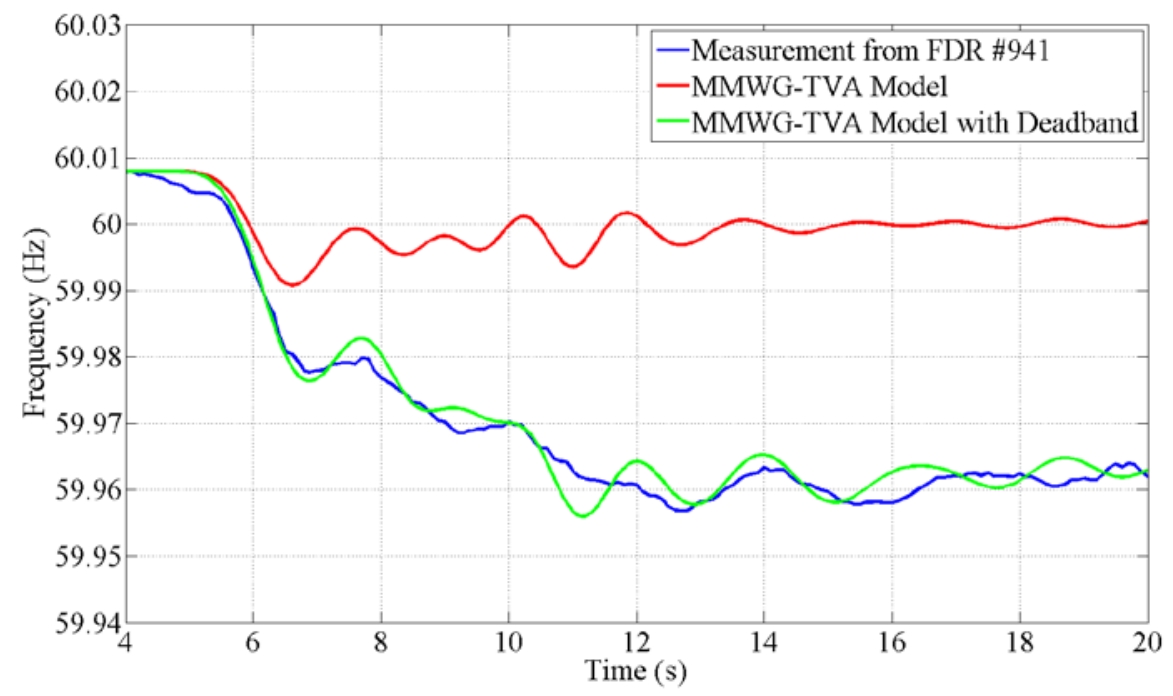

Fig. 14. Case study 1: measurement at Wakeeney, Kansas. 


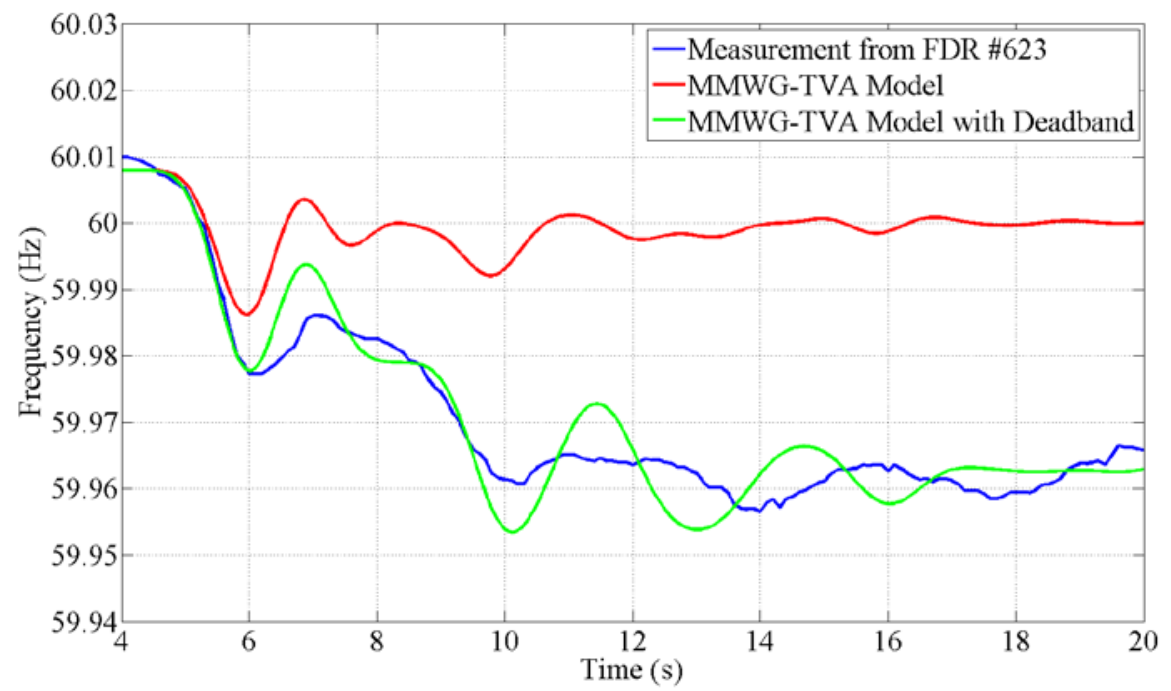

Fig. 15. Case study 1: measurement at Lakeland, Florida.

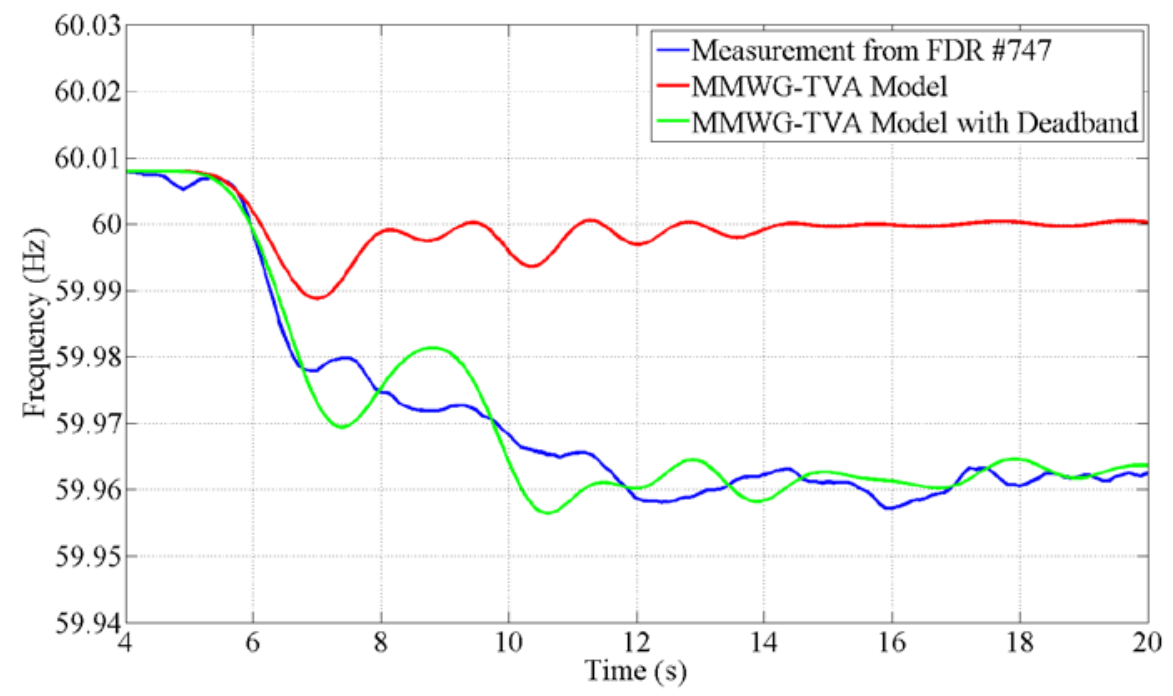

Fig. 16. Case study 1: measurement at Minneapolis, Minnesota. 


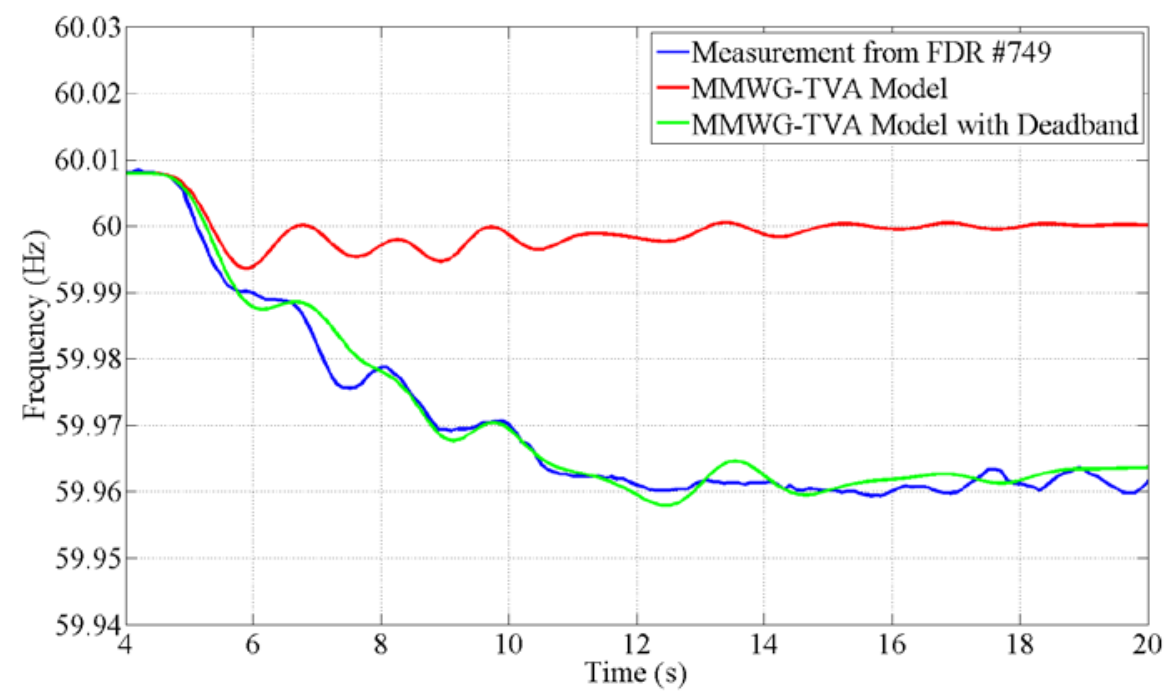

Fig. 17. Case study 1: measurement at Scott City, Missouri.

\subsection{CASE STUDY 2}

Time: 07/28/2013 14:18:40 UTC

Actual event: 1090 MW generation trip at Cook Unit 2 in Michigan

Tripped capacity in simulation: $1060 \mathrm{MW}$

Governor deadband: $33 \mathrm{mHz}$

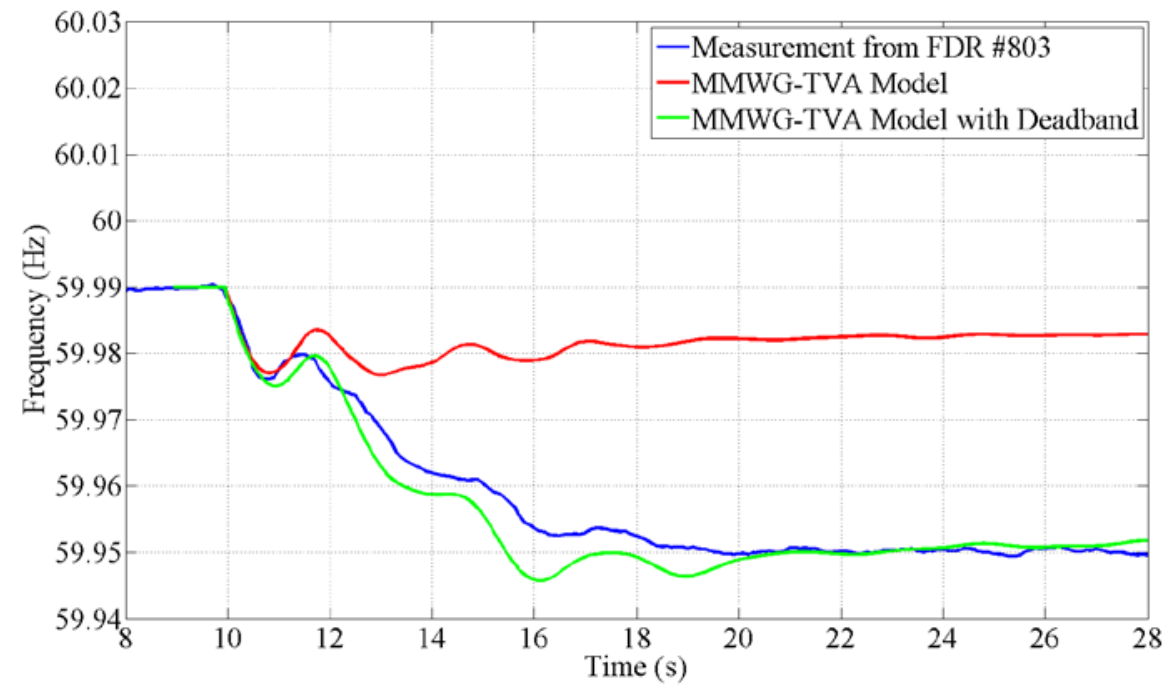

Fig. 18. Case study 2: measurement at Columbus, Ohio. 


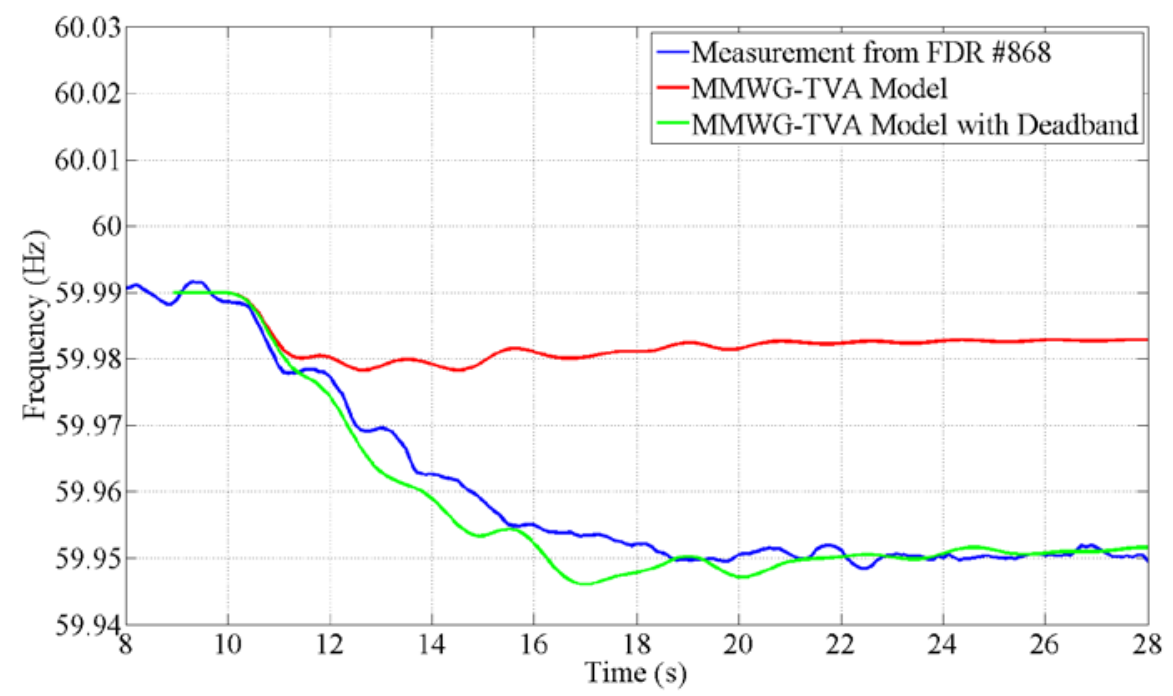

Fig. 19. Case study 2: measurement at Nashville, Tennessee.

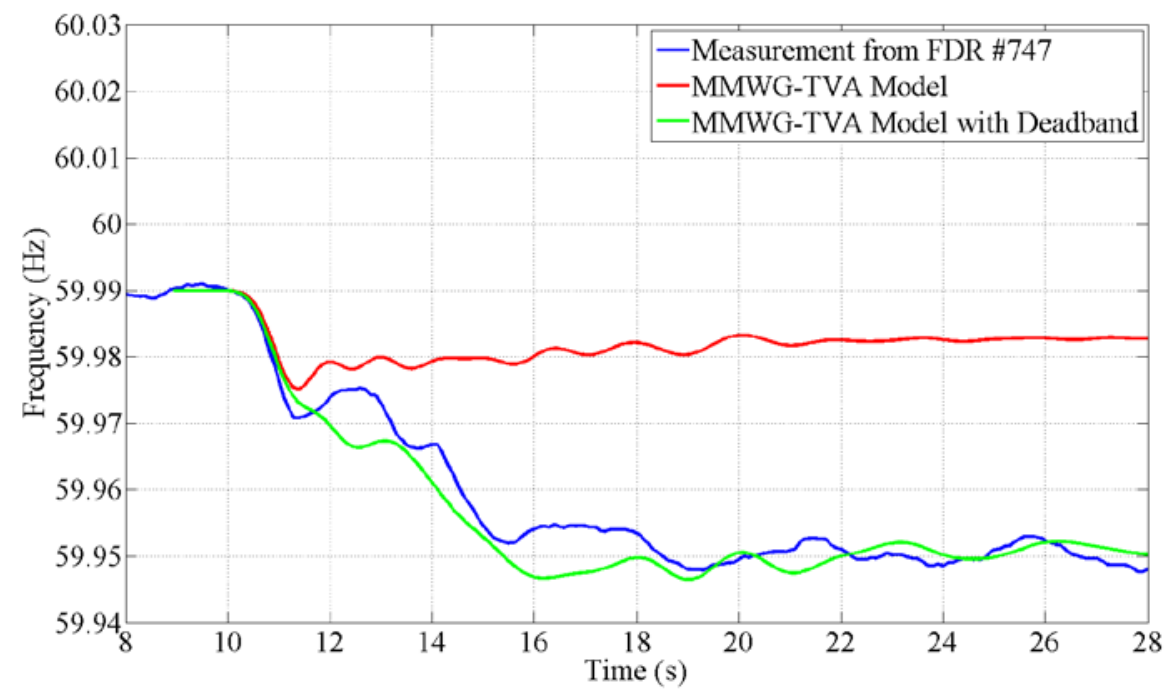

Fig. 20. Case study 2: measurement at Minneapolis, Minnesota. 


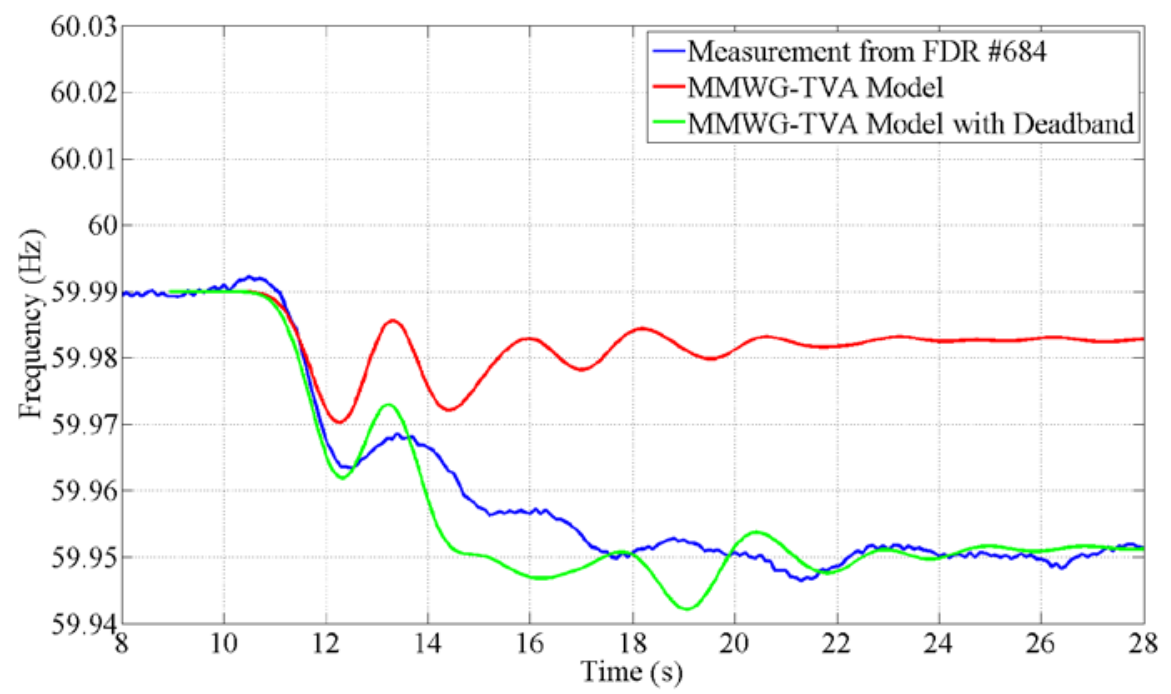

Fig. 21. Case study 2: measurement at Boston, Massachusetts.

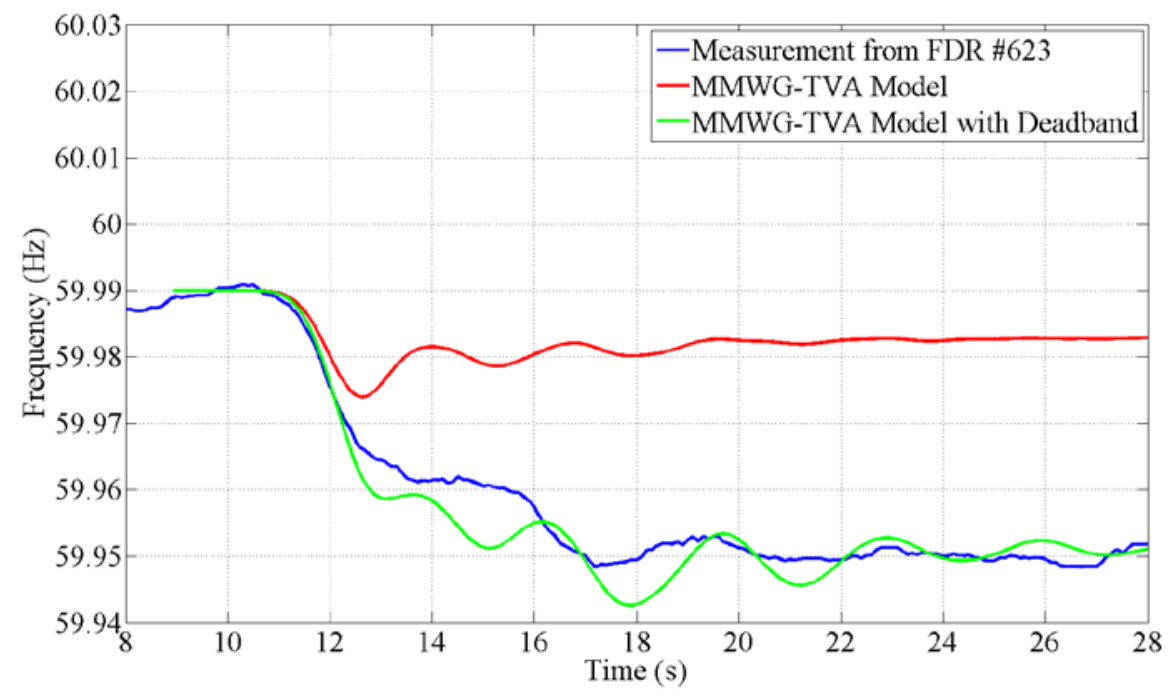

Fig. 22. Case study 2: measurement at Lakeland, Florida.

\subsection{CASE STUDY 3}

Time: 02/12/2013 03:37:15 UTC

Actual event: 693 MW generation trip at Turkey Point Unit 3 in Florida

Tripped capacity in simulation: 693 MW

Governor deadband: $33 \mathrm{mHz}$ 


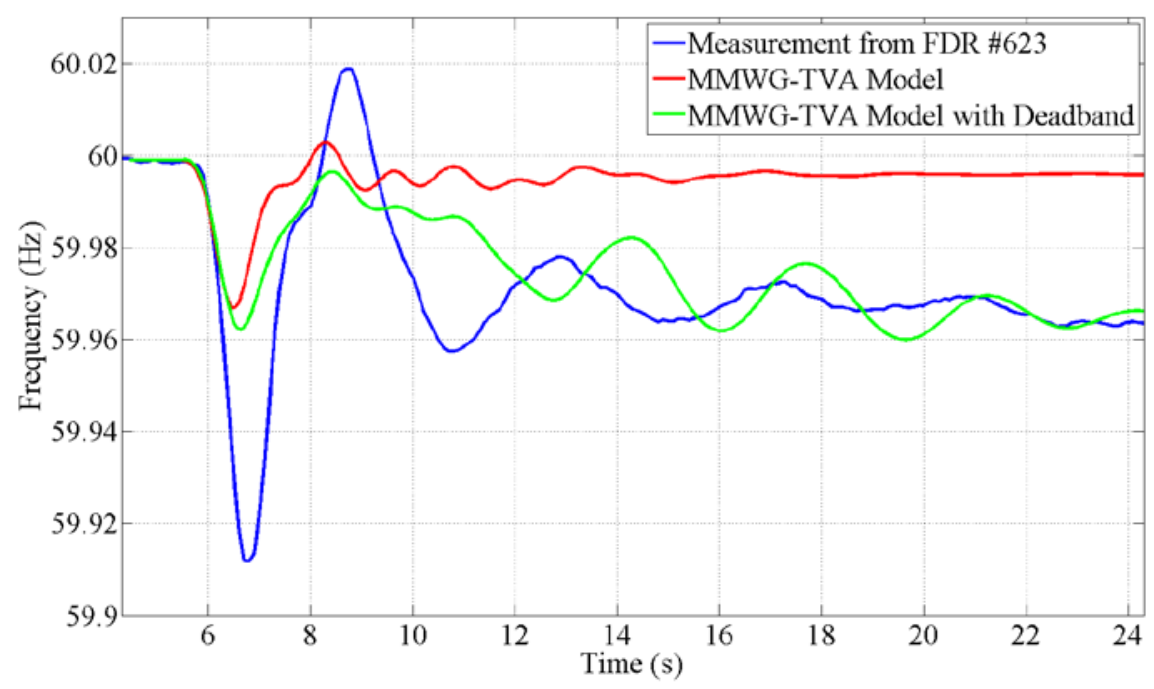

Fig. 23. Case study 3: measurement at Lakeland, Florida.

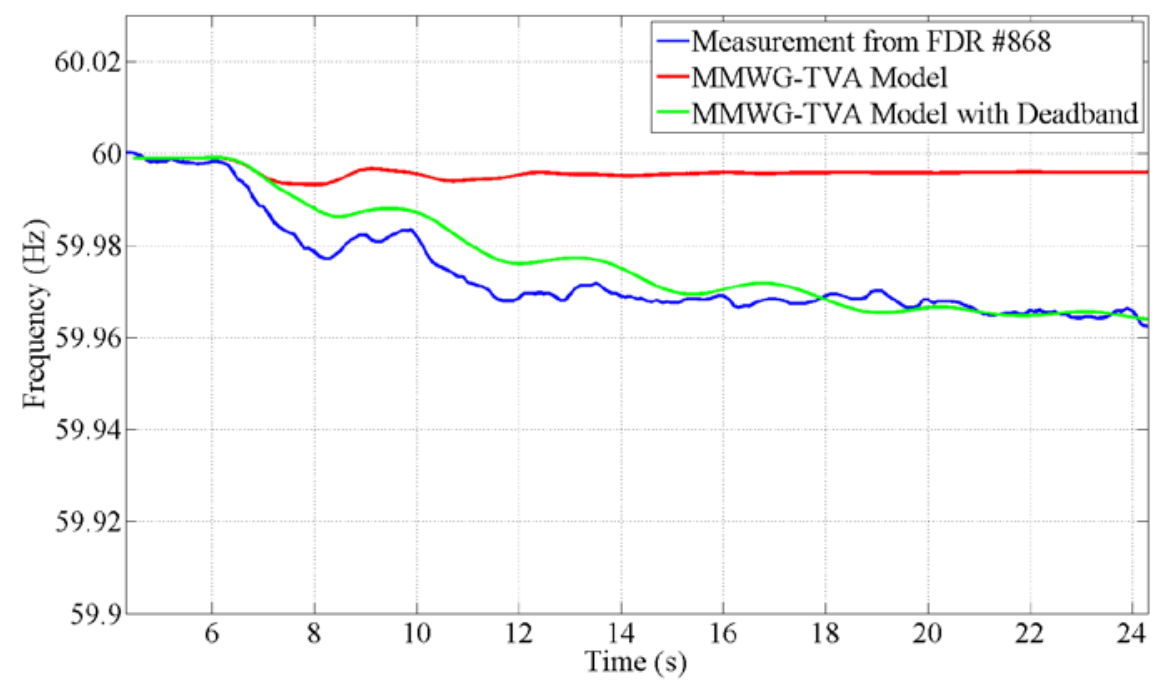

Fig. 24. Case study 3: measurement at Nashville, Tennessee. 


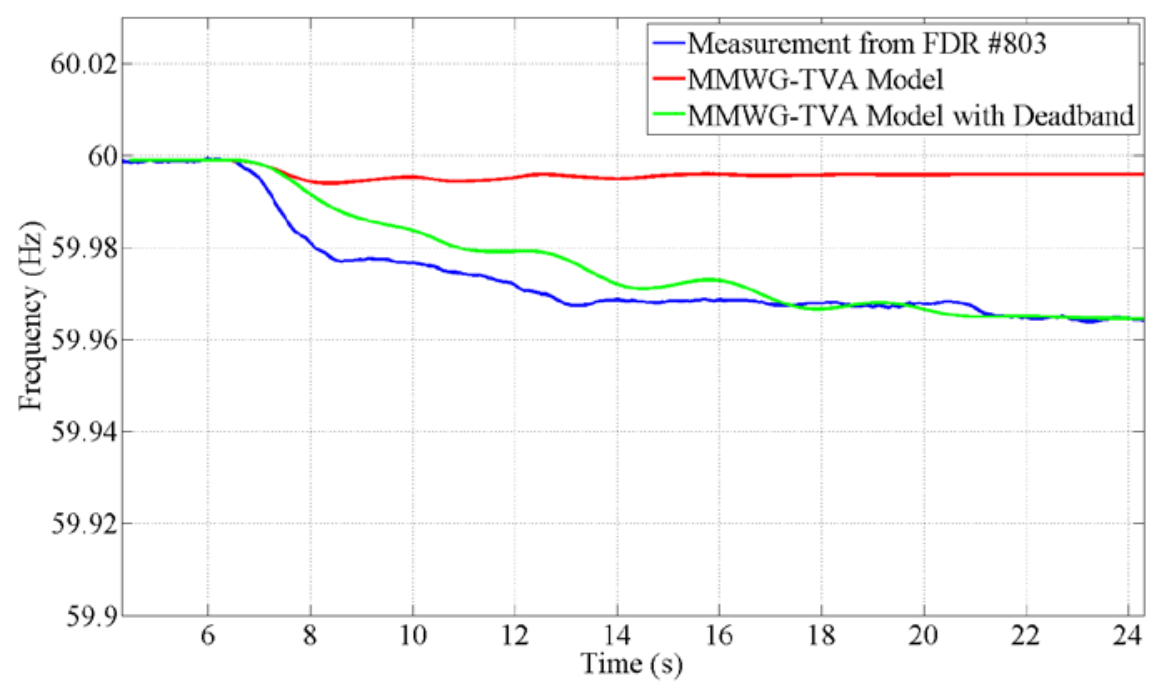

Fig. 25. Case study 3: measurement at Columbus, Ohio.

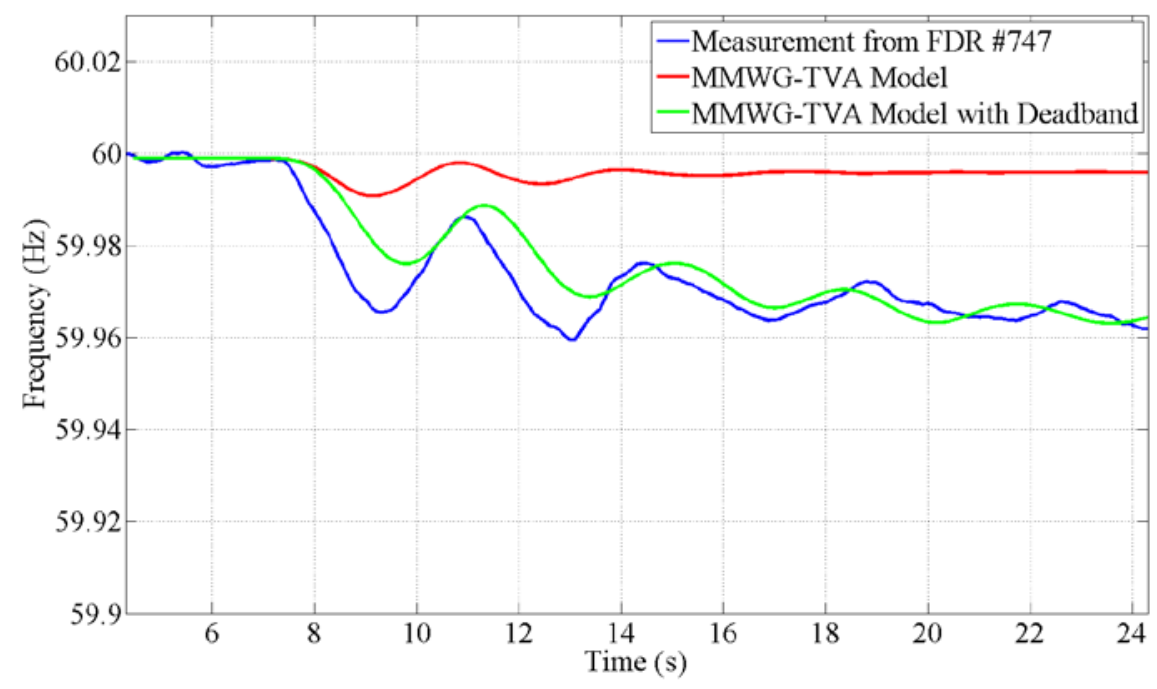

Fig. 26. Case study 3: measurement at Minneapolis, Minnesota. 


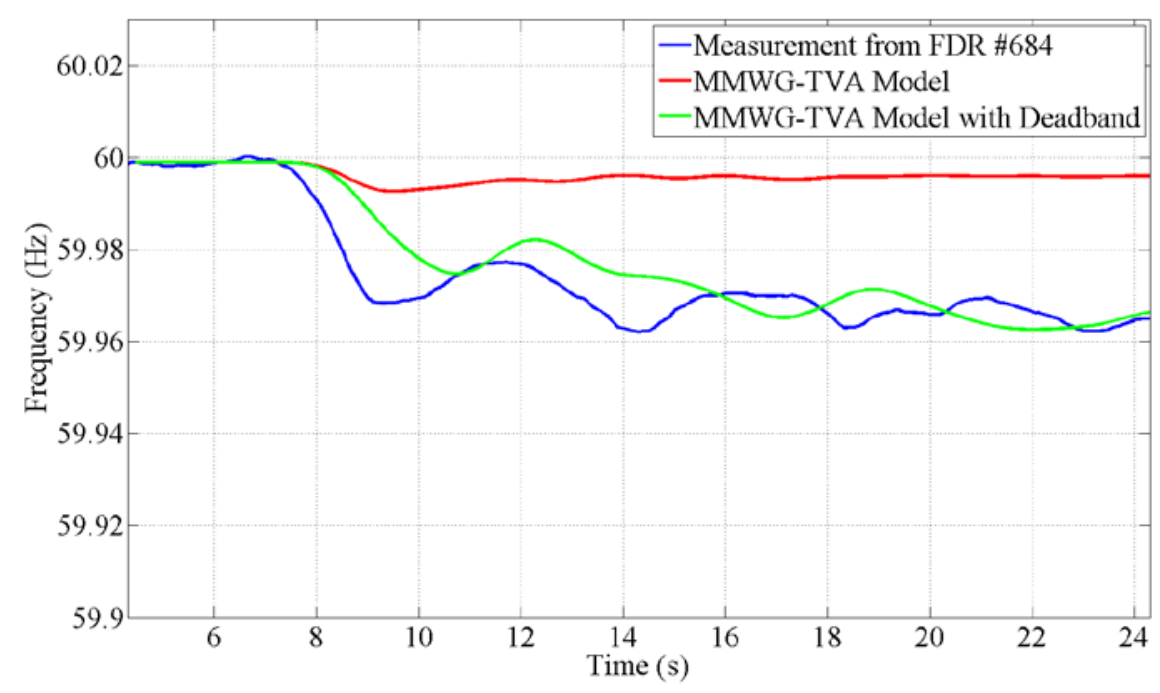

Fig. 27. Case study 3: measurement at Boston, Massachusetts.

\subsection{CASE STUDY 3 WITH REDUCED INERTIA}

It is noted in case 3 that the simulated ring-down slope is less steep than the measurement. A separate simulation is conducted with the machine inertia uniformly reduced to $50 \%$.

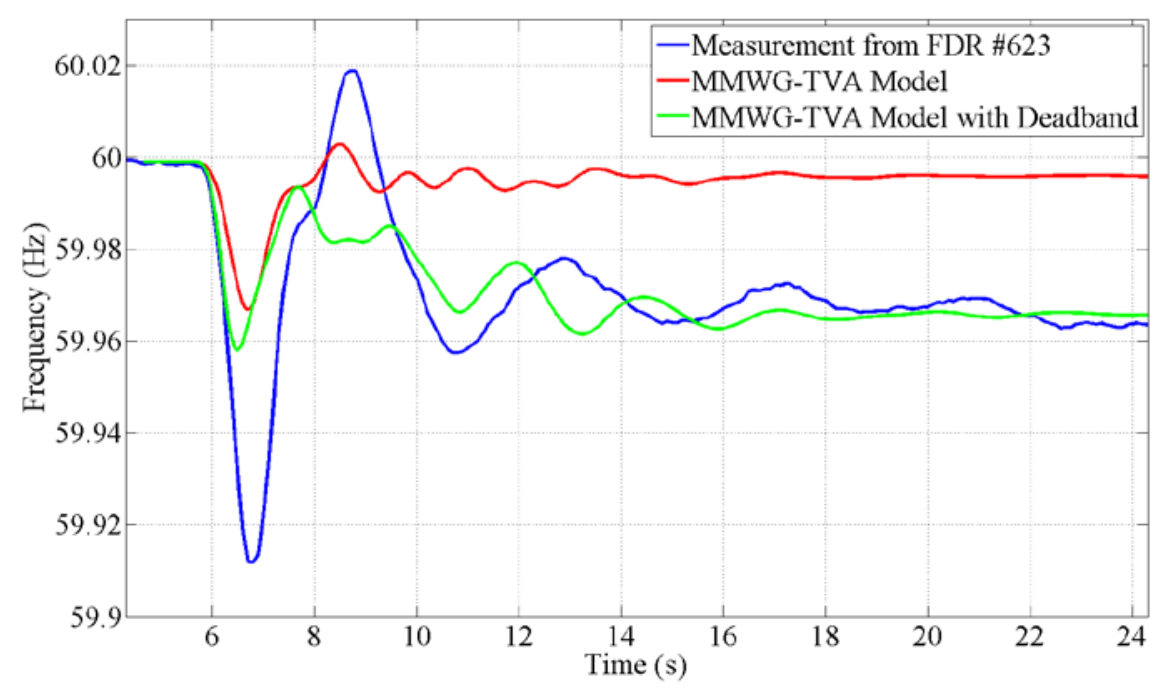

Fig. 28. Case study 3 with reduced inertia: measurement at Lakeland, Florida. 


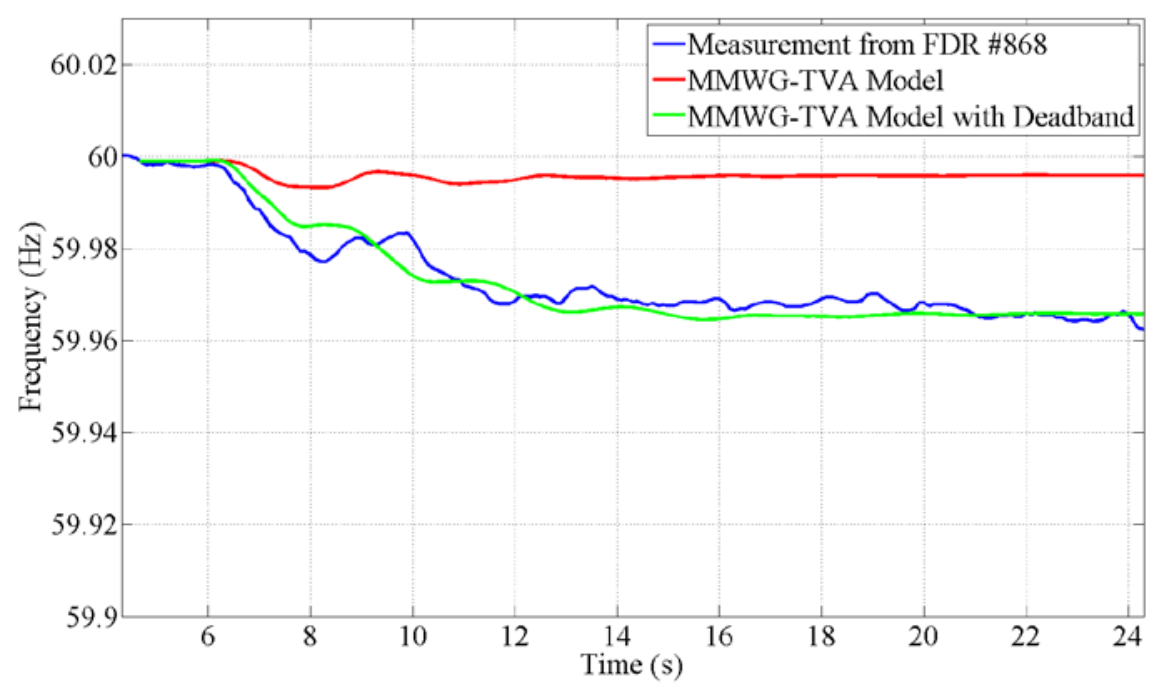

Fig. 29. Case study 3 with reduced inertia: measurement at Nashville, Tennessee.

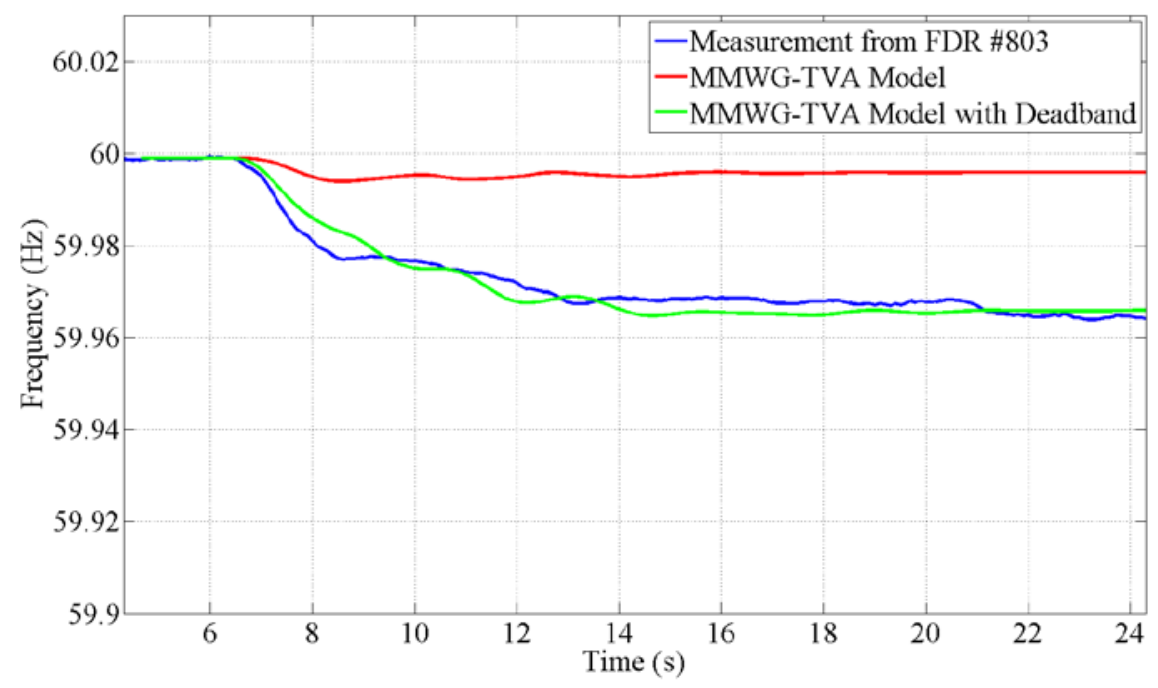

Fig. 30. Case study 3 with reduced inertia: measurement at Columbus, Ohio. 


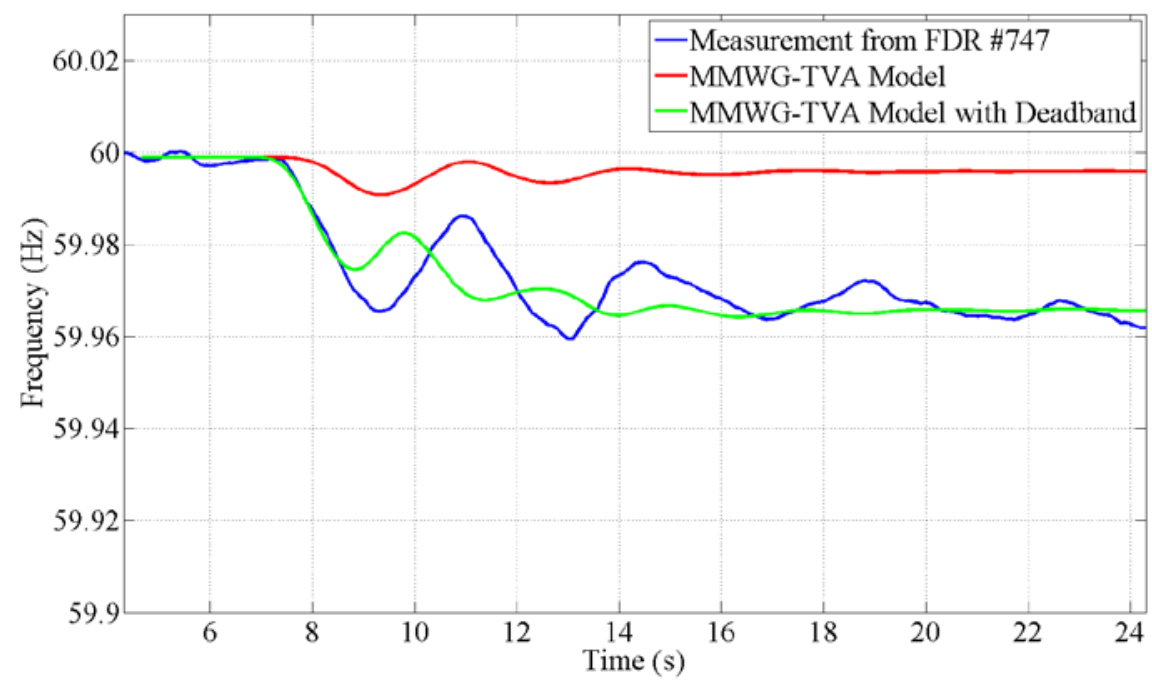

Fig. 31. Case study 3 with reduced inertia: measurement at Minneapolis, Minnesota.

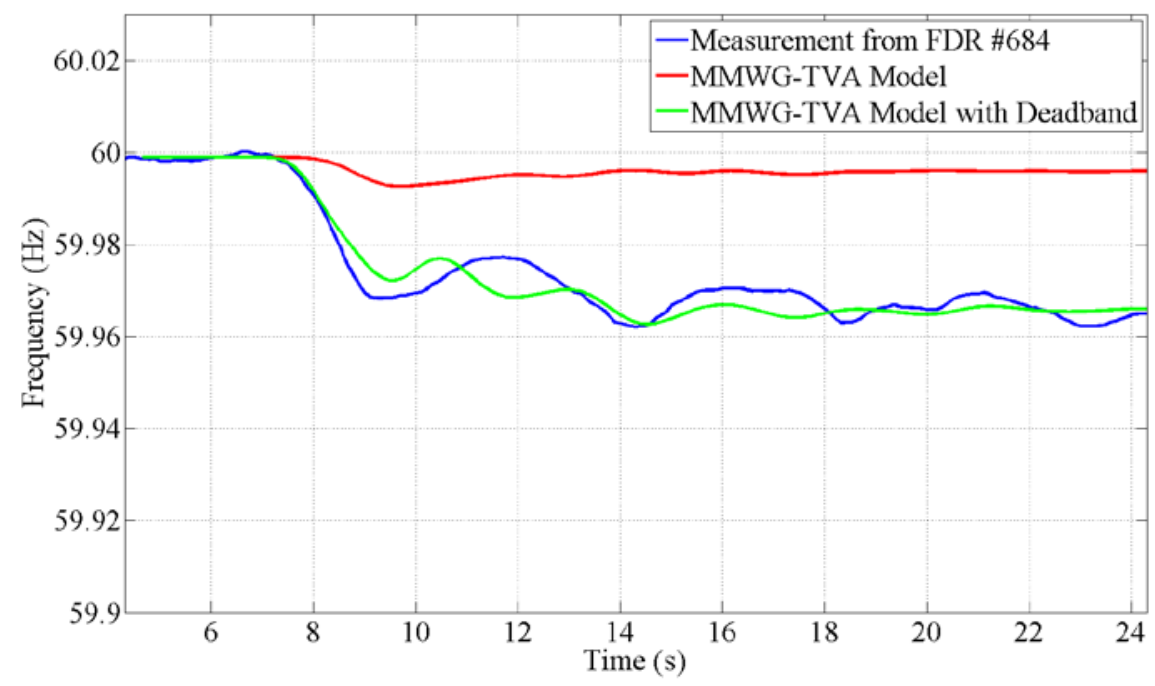

Fig. 32. Case study 3 with reduced inertia: measurement at Boston, Massachusetts.

\section{DISCUSSION}

Through the case studies shown previously, it is concluded that simulated frequency response exhibits closer alignment with measurement by modeling governor deadband. To simulate accurate settling frequency at 16-20 seconds after disturbance, the deadband ranges from 30 to $40 \mathrm{mHz}$ with $K_{t} \approx 42 \%$.

Although the actual power system operates at various conditions, the power system dynamic model can only capture one snapshot of the working condition. This explains in case study 3 that the simulated 
frequency shows less steep ring-down slope: the actual event happens at 03:37:15 UTC, and fewer generators are dispatched. Thus, the total system inertia is smaller than that of the on-peak hour and the inertia response is less strong. Considering the constant shift of operating conditions in the real system, it is not expected that one single dynamic scenario will fit every measurement by simply adding governor deadband. In addition, the assumed uniform deadband size is an approximation of the actual deadband that widely spans in size.

It is also noted that adding governor deadband not only reflects true settling frequency but also simulates a more realistic system damping condition. The turbine governor is essentially generating damping effects on active power and frequency. In a standard simulation, the governor will act once there is frequency deviation. On the contrary, in reality, the governor would not act until the deadband is exceeded. The effect can be roughly interpreted as a time-delay response. Therefore, standard simulations usually have more optimistic damping than reality, and modeling deadband would give a more realistic damping ratio.

It is recognized that the model conversion method described in Sect. 2.2 cannot be extended to all other model types, such as hydro. A more thorough approach to modeling governor deadband is to create userdefined governor models and add a deadband logic on established standard models.

\section{ACKNOWLEDGEMENT}

The authors would like to acknowledge the support of Oak Ridge National Laboratory and the US Department of Energy's Office of Electricity Delivery and Energy Reliability under the Advanced Modeling Grid Research Program.

This work was also supported in part by the Engineering Research Center Program of the National Science Foundation and the US Department of Energy under NSF Award Number EEC-1041877 and the Center for Ultra-Wide-Area Resilient Electric Energy Transmission Networks (CURENT) Industry Partnership Program.

\section{REFERENCES}

1. $\quad$ N. W. Miller et al., "Eastern frequency response study,” National Renewable Energy Laboratory (NREL), Golden, Colo., May 2013.

2. L. Pereira and et al., "New thermal governor model selection and validation in the WECC," IEEE Trans. Power Syst. 19(1), 517-523, Feb. 2004.

3. L. Chen, P. Markham, and Y. Liu, "Wide-area dynamic model validation using FNET measurements,” in Proc. 2012 IEEE PES Innovative Smart Grid Technologies (ISGT), pp.1-7.

4. D. N. Kosterev and D. Davies, "System model validation studies in WECC," in Proc. 2010 IEEE Power and Energy Society General Meeting, pp.1-4.

5. G. Kou et al., "Developing Generic Dynamic Models for the 2030 Eastern Interconnection Grid,” in Proc. 2014 IEEE PES Transmission and Distribution Conference and Exposition (T\&D), in press.

6. North American Electric Reliability Corporation (NERC), Frequency response initiative reportthe reliability role of frequency response, NERC, Atlanta, Ga., Oct. 2012. 
7. J. Undrill, "Power and frequency control as it relates to wind-powered generation,” John Undrill LCC, Dec. 2010.

8. G. Kou et al., "Developing Generic Dynamic Models for the 2030 Eastern Interconnection Grid," Oak Ridge National Laboratory, Oak Ridge, Tenn., Dec. 2013.

9. J. M. Undrill and T. F. Laskowski, "Model Selection and Data Assembly for Power System Simulations,” IEEE Trans. Power Apparatus and Systems, vol. PAS-101, no. 9, 3333-3341, Sept. 1982.

10. Siemens Power Technologies International, PSS/E 33.1.1, Program Application Guide Volume 2, May 2012.

11. Y. Liu, “A US-Wide Power Systems Frequency Monitoring Network,” in Proc. 2006 IEEE Power Systems Conference and Exposition, pp. 159-166.

12. P. M. Anderson and A. A. Fouad, Power System Control and Stability, Ames: The Iowa State University Press, 1977. 